\title{
Review
}

\section{Surveying the Landscape of Huntington's Disease Mechanisms, Measurements, and Medicines}

\author{
Zachary R. Crook and David E. Housman* \\ Koch Institute for Integrative Cancer Research, Massachusetts Institute of Technology, Cambridge, MA, USA
}

\begin{abstract}
Though 20 years have now passed since the cloning of the huntingtin gene (HTT), there remains no treatment for Huntington's Disease (HD) that alters the course of disease or lifespan of patients. The reasons for this are manifold, and likely have to do with the diverse cellular pathways disrupted by mutant HTT (mHTT) protein expression. Furthermore, the evaluation of efficacy using a putative intervention is complex, largely due to the slow course of disease and variability in the classic techniques for evaluating patient symptoms and quality of life, which make the patient populations and duration of trials particularly imposing. However, there are signs for hope both in the clinic and at the bench. This review serves three purposes. It discusses the known cellular pathologies in HD, the current and upcoming methods for clinical evaluation of disease progress, and the tested and untested interventions proposed to counter the progression in animal models and patients. With the vast knowledge of pathology accumulated over two decades of modeling HD in animals and following it in patients, as well as the advances in intervention techniques both pharmaceutical and genetic, there is reason for optimism in the field. Such optimism can only be tempered by the lack of success in the clinic to this point, though patients, scientists, and clinicians all remain enthusiastic about each new trial, and progress can only continue until an effective treatment is found.
\end{abstract}

Keywords: Neurodegeneration, Huntington's disease, disease mechanisms, therapeutics, aggregation, chaperones, excitotoxicity, gene therapy

\section{INTRODUCTION}

Huntington's Disease (HD) is a progressive, fatal neurodegenerative disorder, characterized by motor, cognitive, behavioral, and psychological dysfunction. Affecting approximately 1 in 10,000 people worldwide, HD is caused by an expansion within a poly(CAG) tract in exon 1 of the huntingtin (HTT) gene. Age of onset is roughly inversely correlated with the length of the CAG tract [1-3]. Disease occurs with $100 \%$ penetrance when 40 or more CAG repeats are present [2]. Pathology in HD is characterized by

\footnotetext{
*Correspondence to: David E. Housman, Koch Institute for Integrative Cancer Research, Massachusetts Institute of Technology, 500 Main Street, Room 76-553, Cambridge, MA 02139, USA. Tel.: +1 617253 3013; E-mail: dhousman@mit.edu.
}

progressive neurodegeneration, particularly within the cortex and the striatum (caudate and putamen), leading to the characteristic motor dysfunctions of HD, such as uncontrolled limb and trunk movements, difficulty maintaining gaze, and general lack of balance and coordination [4], as well as cognitive problems, behavioral abnormalities, and psychological dysfunction. Although 20 years have passed since the discovery of the causative gene, there is no disease modifying treatment for HD. Treatments providing temporary symptom relief are the only interventions currently available to patients. Significant strides have been made in understanding the gene and its dysfunction when mutated, but the complexities of the cellular pathology observed in HD make it clear that curing HD will not be a simple task. 


\section{mHTT AGGREGATES: TOXIC, OR BYPRODUCT?}

After HTT was cloned and mutant HTT (mHTT) expressed in mice (a variety of which are illustrated in brief in Fig. 1) to generate the first genetic animal model [5-8], its subcellular localization was investigated. This led to the discovery that $m H T T$-expressing cells contain inclusions, small $(\sim 1 \mu \mathrm{m})$ aggregates that stain strongly for mutant HTT protein (mHTT) and are found in either the cytosol or nucleus, depending on the model. They were also seen in HD patient samples [9] and became one of the hallmarks of neuropathology.

As reviewed by Yamada et al. [10], there are at least nine disorders involving a coding polyglutamine (polyQ) expansion: Huntington's Disease, spinal and bulbar muscular atrophy (SBMA, also known as Kennedy's Disease), dentatorubral-pallidoluysian atrophy (DRPLA), and spinocerebellar ataxia (SCA) $1,2,3,6,7$, and 17 . There is no overarching pattern to their linkage or even the function of the proteins involved. This results in vastly different protein contexts in which the polyQ tracts are embedded, which likely leads to the different regional susceptibilities involved. The SCA diseases tend to cause degeneration in the cerebellum and brainstem, but with variable pathologies, including basal ganglia involve-

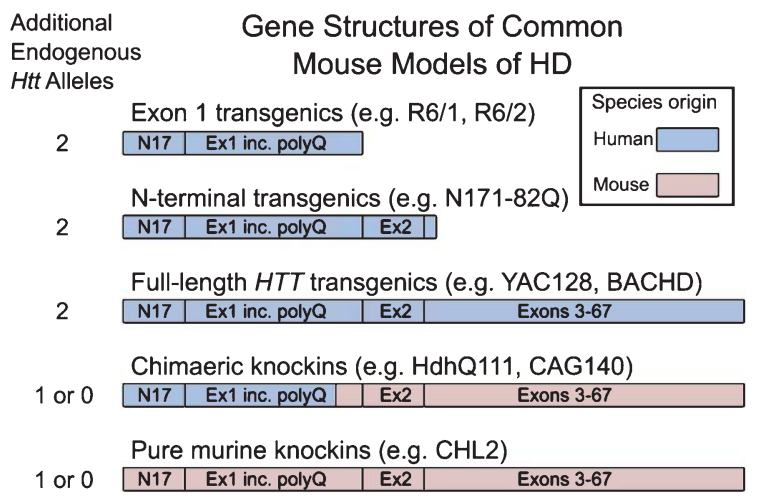

Fig. 1. Gene structure of common mouse models of HD. There are many genetic mouse models of HD. In general, they can be divided into 3 categories. Those with the most striking pathology and lethality are the Exon 1 and N-terminal transgenics (R6/2 and N171-82Q are most common). Full-length transgenic strains use human $m H T T$ as a transgene under endogenous human transcriptional control. YAC128 has been used most commonly in this group. Knockin strains can be subdivided into those with human DNA in exon 1 (HdhQ111 is a prominent example; CAG140 is also known as HdhQ140) versus those with pure mouse $\mathrm{mHtt}$ and only an expanded CAG tract knocked in to the endogenous locus, such as CHL2 (also known as HdhQ150). Additional endogenous $H t t$ alleles are listed as a reminder that the transgenic strains have both $\mathrm{Htt}$ alleles present and unaltered, while the knockin strains have 1 (if $m H t t$ is heterozygous) or 0 (if $m H t t$ is homozygous). ment (striatum and globus pallidus) in SCA1, SCA3, and SCA17. DRPLA strongly affects the globus pallidus and other forebrain subcortical structures, while SBMA is primarily a disease of lower motor neuronal and spinal motor nuclei loss. All of the known polyQ diseases are neurodegenerative (which may be a result of the postmitotic nature of neurons lacking the ability to remove damaged proteins through dilution upon division), and they all demonstrate neuronal intranuclear inclusions and eventual neuronal death as a result of the gain of toxic function imparted by the polyQ expansion.

Like wild type HTT (wtHTT), mHTT is largely cytosolic [11], but N-terminal mHTT, either the result of cleavage or due to the expression of an $\mathrm{N}$-terminal fragment of mHTT, can form inclusions in the cell soma or nucleus [12-14]. These inclusions are presumed to be rich in $\beta$-sheet amyloid, as they bind thioflavin T and congo red, and the CD spectra of isolated polyQ amyloid is demonstrably $\beta$-sheet rich [15]. mHTT aggregation is currently thought to begin by seeding of small oligomers, facilitated by the amphipathic helical N17 region and which can be modulated by posttranslational modifications in the region. Once there is a local increase in the concentration of polyQ regions in close apposition, the structure reorganizes to a more regular $\beta$-sheet amyloid [16, 17]. In support of this, congo red, which binds amyloid and mHTT inclusions in patient samples [18], was shown to inhibit the formation of mature amyloid fibrils [19]. Many groups theorized that these inclusions were the source of mHTT toxicity; for example, it was tested whether in vivo treatment of HD model mice with congo red could prevent toxicity, but the data were inconclusive, as one group showed improvement of weight, survival, and aggregate formation, while a second failed to show any of those improvements [20, 21]. These, and other studies, caused the field to re-think the relationship between inclusions and HD.

In an elegant imaging study, it was demonstrated that, in PC12 cells transfected with an exon 1 fragment containing $47 \mathrm{Q}$, inclusion formation correlates with survival, rather than toxicity. Instead, soluble mHTT levels are a stronger predictor of death [22]. Meanwhile, in mouse models of HD and in two other polyQ disease models, aggregates either fail to correlate with neuron death or actually correlate with survival [23-25]. Perhaps most compelling is an Nterminal mouse model known as shortstop (Ss). Ss mice were the result of an unintended truncation in exon 2 during integration of a full-length YAC construct of $m H T T$, resulting in the expression of a short 
$\mathrm{N}$-terminal protein reminiscent of that in the highly toxic R6/2 line, albeit with some of exon 2 present. Like R6/2 mice, inclusions are pervasive in neurons, but this line exhibits no behavioral or neuropathological defects [26], although this may also be related to transgene expression levels and/or background strain, as a different transgenic mouse line expressing a protein of the same length under a strong prion promoter does indeed show reduced lifespan [27]. Later work showed that Ss constructs in vitro don't form soluble oligomers and more readily interact with the chaperone Hsp70, suggesting that oligomers, now thought to be the toxic species, are not a kinetically favorable state for Ss constructs. Other N-terminal mHTT constructs known for toxicity readily form oligomers [28]. Yeast models provide additional insight into the regulation of aggregation kinetics, as they suggest there are distinct classes of genes either facilitating small oligomer formation or the transition from oligomers to inclusions. Knockouts in the former pathway were protective, while loss of those in the latter enhanced the 103Q construct's toxicity [29].

All told, there is strong evidence that inclusions appear in the presence of neurotoxic species in patients and most mouse models, but there is stronger evidence that this is little more than correlative, and that such inclusions may be protective or benign. One might think of the inclusions as the cell's landfill. If there is garbage (mHTT) in the cell, it is better that it ends up in the landfill (inclusions) rather than littering the streets (cytosol and nucleus). If an intervention is altering the size of the landfill/inclusion, this makes it crucial to distinguish whether the trash is being disposed of (for example, by autophagy), which would be healthy, or whether the garbage now isn't getting to the landfill in the first place (remaining as oligomers), increasing toxicity.

\section{SEQUESTRATION OF PROTEINS IN INCLUSIONS}

The study of oligomer seeding and amyloid inclusion formation in vitro has helped better define the polyQ-driven kinetics of N-terminal mHTT aggregation, but in vivo, these inclusions can have quite complex structures and are not simple amyloid fibrils. The core of such inclusions is largely made of N-terminal mHTT fragments as well as other small proteins including ubiquitin and Hsp40 [30]. Ubiquitination of inclusions is not necessary for their formation, though, as both model mice and juvenile cases demonstrate mHTT+ inclusions that stain negative for ubiquitin $[9,31,32]$. The surface of these aggregates, once established, contains full-length wtHTT and mHTT, and also Hsp70, dynamin, the proteasome, and others [30]. These more surface-oriented proteins are susceptible to protease digestion, while the core proteins are not.

Many believe that some of the molecular pathology is the result of proteins being titrated out of solution in the cell, caught in these aggregates. Proteins found in aggregates include mTOR, p53, Mdm2, Hsp70, caspases, and nuclear pore proteins [33, 34]. mHTT also aberrantly interacts with many transcription factors (reviewed in [35]) resulting in transcriptional profile alterations that have wide-ranging effects (to be discussed later). However, bound transcription factors were not found in macroscopic aggregates [36] and soluble monomers found in the nucleus can suppress transcription [37], so sequestration in an aggregate is not required for mHTT to disrupt a transcription factor's function.

\section{mHTT, MISFOLDED PROTEINS, AND CHAPERONES IN HD}

As mentioned above, mHTT is a target for chaperones, proteins that aid in the proper folding or degradation of misfolded proteins. The presence of heat shock proteins (Hsps) and ubiquitin in insoluble inclusions demonstrates that cells are attempting to refold or mediate degradation of $\mathrm{mHTT}[33,38]$, and there is a wealth of data on mHTT's effects on chaperone pathways and vice-versa (Fig. 2).

The interaction of Hsps and inclusion bodies seems to be polyQ and age-dependent. Hsps are mainly found on the periphery of inclusion bodies [30], and are only found there in older HD model mice [39]. Hsp70 may play an active role in facilitating the degradation of mHTT under normal HD conditions, as its knockout significantly worsens symptoms of HD mice and increases the size of inclusions [40], though it is possible that these effects are indirect through dysregulation of proteostasis. On the other hand, Hsp90 seems to protect mHTT from proteasomal degradation, and its knockdown reduces mHTT levels [41]. Basal levels of Hsps may contribute to the specific toxicity of medium spiny neurons (MSNs) in the striatum, as Hsp70 is particularly highly expressed in the cerebellum, a tissue with little to no neuropathology in HD [42].

Drosophila models have been especially instructive for the relationship between Hsp70 proteins, ubiq- 


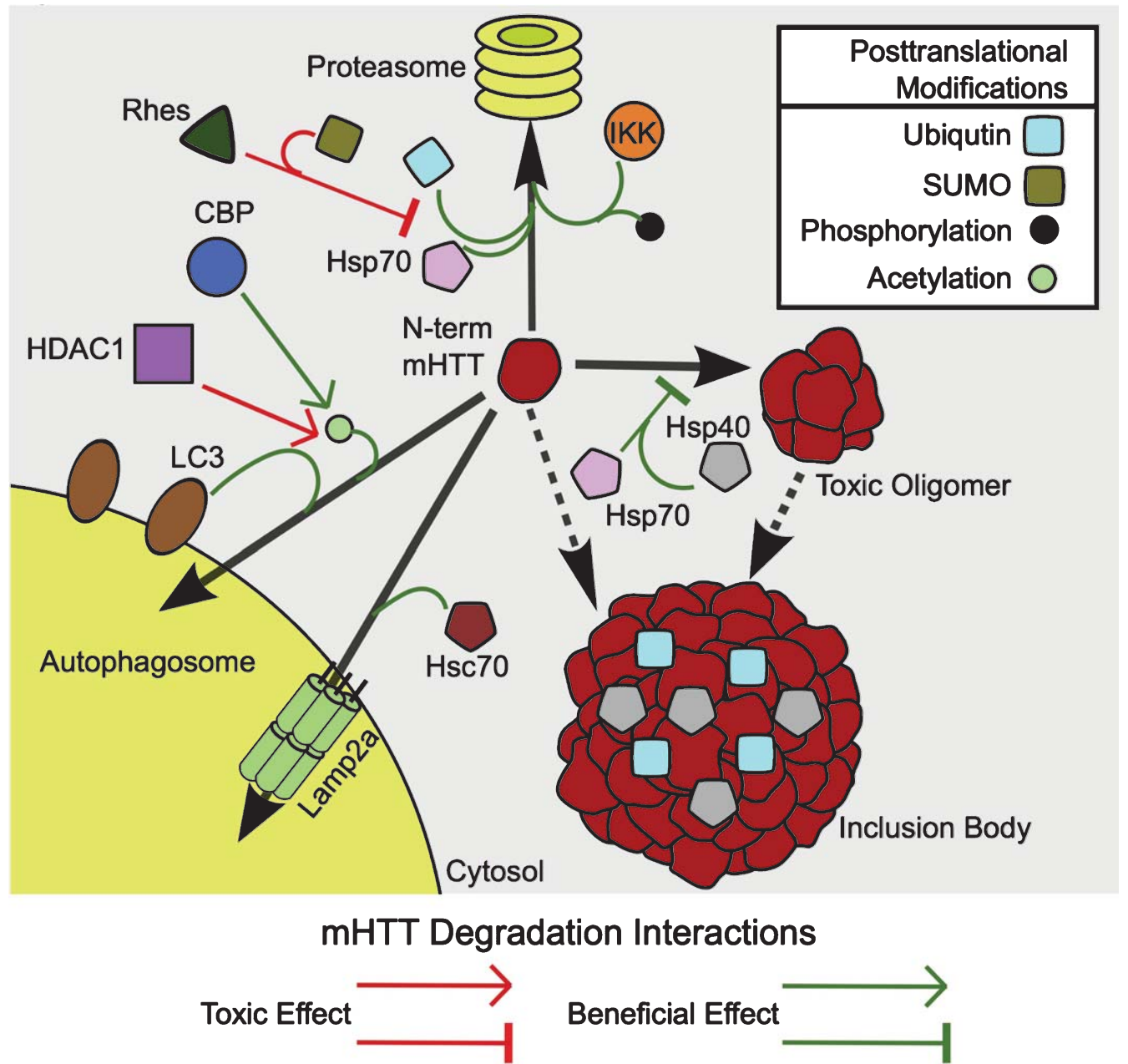

Fig. 2. Disposal of mHTT. Cells can safely dispose of mHTT through one of four routes. Inclusion bodies represent a relatively safe place for mHTT. Non-toxic isoforms of mHTT (like Shortstop) bind Hsp70 and Hsp40 readily and do not form toxic oligomer species, and Hsp70/40 overexpression suppresses toxic oligomer formation. However, non-toxic mHTT isoforms still form inclusion bodies, so either Hsp70/40 facilitate oligomer sequestration into inclusion bodies, or they prevent toxic oligomerization, allowing mHTT to join inclusion bodies through alternate pathways. The proteasome can also degrade mHTT after Hsp70-aided ubiquitination and IKK-mediated phosphorylation, while SUMOylation by RHES opposes it. Autophagy can also be employed to destroy mHTT. Acetylated mHTT (regulated by CBP and HDAC1) is a target for LC3-mediated macroautophagy, while Hsc70 promotes passage of mHTT through Lamp2a channels for chaperone-mediated autophagy. These routes of disposal are clearly insufficient as cells age, but experiments demonstrating enhanced toxicity upon impairment of these pathways demonstrate that they each contribute to survival.

uitination, and neurodegeneration. PolyQ-expanded androgen receptor (AR), HTT, and MJD1 (the fly homolog for the gene mutated in Machado-Joseph Disease) all cause degeneration of the retina when expressed in the fly eye [43-45]. When Hsp70 is overexpressed in the context of many of these polyQ proteins, degeneration is suppressed, while its deletion or dominant negative expression exacerbate the degenerative phenotype. Hsp70 does not function alone in this regard, as the cochaperones HIP and CHIP facilitate ubiquitination of polyQ substrates [45, 46]. Interestingly, CHIP, an E3 ubiquitin ligase functioning through Hsp70, appears to depend on the protein context for its activity. CHIP overexpression can suppress toxicity of polyQ mHTT, but not that of a protein only consisting of an HA-tagged polyQ tract of identical length [45]. Furthermore, the ubiquitination of polyQ proteins by Hsp70-aided processes also depends on SUMOylation [43]. This may be particularly relevant to HD because SUMO, a similar protein to ubiquitin, was recently found to be conjugated to mHTT by Rhes in human cells. Rhes is a striatal-specific protein, and its SUMOylation of mHTT is competitive with pro-survival ubiquitination [47]. 
Given the interesting data on mHTT's interaction with Hsps (particularly Hsp70), many groups have tested whether the overexpression of Hsps is protective in mammalian HD models. Tissue culture cells overexpressing $\mathrm{Hsc} 70, \mathrm{Hsp} 40$, and $\mathrm{Hsp} 84$ are protected from a polyQ construct $[39,48]$, but mice were not so easily treated by single-gene overexpression. Unlike data seen in flies, even a massive congenital overexpression of $H s p 70$ only modestly rescued the weight loss phenotype of R6/2 mice, without affecting neuropathology $[49,50]$. It's possible that in adult neurons, multiple Hsps need to be overexpressed if a significant alteration of mHTT aggregation kinetics is to be seen. To that end, overexpression of a constitutively active $H s f 1$, a positive regulator of many Hsps, was tried in R6/2 mice. Though this transgene did not express well in the $\mathrm{CNS}$, the mice survived longer and showed reduced inclusion body formation in skeletal muscle [51], indicating that modulating levels of Hsps may be a viable strategy in HD.

However, a note of caution is warranted regarding modulation of proteostasis for a therapeutic option. It is plausible that steady state increases in a person's proteostasis capacity could promote tumorigenesis, as it is well known that many oncoproteins are clients of Hsp90 or other chaperones [52]. While tumors are commonly seen to overexpress chaperone proteins, we are unaware of whether pharmacologic upregulation of chaperone activity has been shown to induce tumorigenesis. However, it is worth mentioning that polyQ disease patients (including both manifest and premanifest HD) have roughly half the rate of cancer, after correcting for age and other factors, as family members without the polyQ expansion [53]. It is therefore worth investigating whether mHTT's disruptive effect on proteostasis is preventing chaperone pathways from facilitating hypertrophy and uncontrolled cell division. If this were true, rescue of this pathway may also lead to normalization, or even a further elevation, of cancer incidence rates, though this is purely speculative.

The classical chaperones Hsp40, 70, and 90 are not the only members of the protein folding machinery known to interact with and modify mHTT toxicity. The chaperonin $\mathrm{TRiC}$ is a large $\sim 1 \mathrm{MDa}$ complex that actively refolds proteins through sequestration within a cavity, providing an optimal entropic folding environment [54]. It may work by exposing client proteins to a highly hydrophilic environment, essentially preventing cargo from "bumping into" other proteins or lipids and allowing secondary and tertiary folding to take place in seclusion. Initially, client protein interaction takes place through the apical lid subunit that tends to bind hydrophobic, disordered proteins. Its interaction with mHTT was established when overexpression of TRiC subunits in yeast prevented N-terminal mHTT constructs from aggregating [55]. Interestingly, this only occurred when all 8 subunits were expressed, indicating that this may require an intact complex. Further work, though, showed that the apical domain alone can suppress aggregation and toxicity [56, 57], even when applied exogenously to the cell culture media. Clearly the apical domain alone would have a very different function than an intact TRiC, and it is possible that apical domains of TRiC subunits simply suppress toxicity by interacting with mHTT in such a way that it alters aggregation kinetics rather than actively refolds it.

All told, chaperones and chaperonins are responsible for maintaining protein folding homeostasis, and there is sufficient evidence that not only is protein folding deranged in $m H T T$-expressing cells, but that toxicity can be ameliorated by artificially increasing the cell's capacity to deal with misfolded proteins.

\section{PLEIOTROPIC TRANSCRIPTIONAL PROFILE CHANGES IN mHTT-EXPRESSING CELLS}

Shortly after the cloning of the causative gene, postmortem HD patient brain samples were analyzed for levels of neurotransmitter receptors to investigate the cause of the complex motor and psychiatric symptoms displayed by patients. Several receptors expressed on the vulnerable MSNs demonstrated robust reductions, particularly dopamine receptors D1 and D2 [58, 59]. Intracellular markers of these neurons were also reduced, namely substance $P$ and enkephalin [60]. Even interneurons, spared from cell death, are nonetheless subject to dysregulation in the form of reduced neuronal NOS and somatostatin levels [61]. These receptor or antigen reductions were determined to be not simply total tissue loss, but the result of reduced transcripts on a cell-by-cell basis.

Reduced transcript levels of receptors led to studies on the mechanism of transcriptional dysregulation in HD (Fig. 3). Many groups have established aberrant interactions between $\mathrm{mHTT}$ and the transcription factors CBP, TBP, p53, NCoR, and Sp1, in addition to some of the core transcriptional machinery $[35,62]$. Additionally, the transcriptional repressor of neuronal genes REST/NRSF, normally sequestered in the cytosol by a complex including wtHTT, cannot efficiently form a complex with mHTT. Due to mHTT's reduced ability to bind HAP1, another component of 


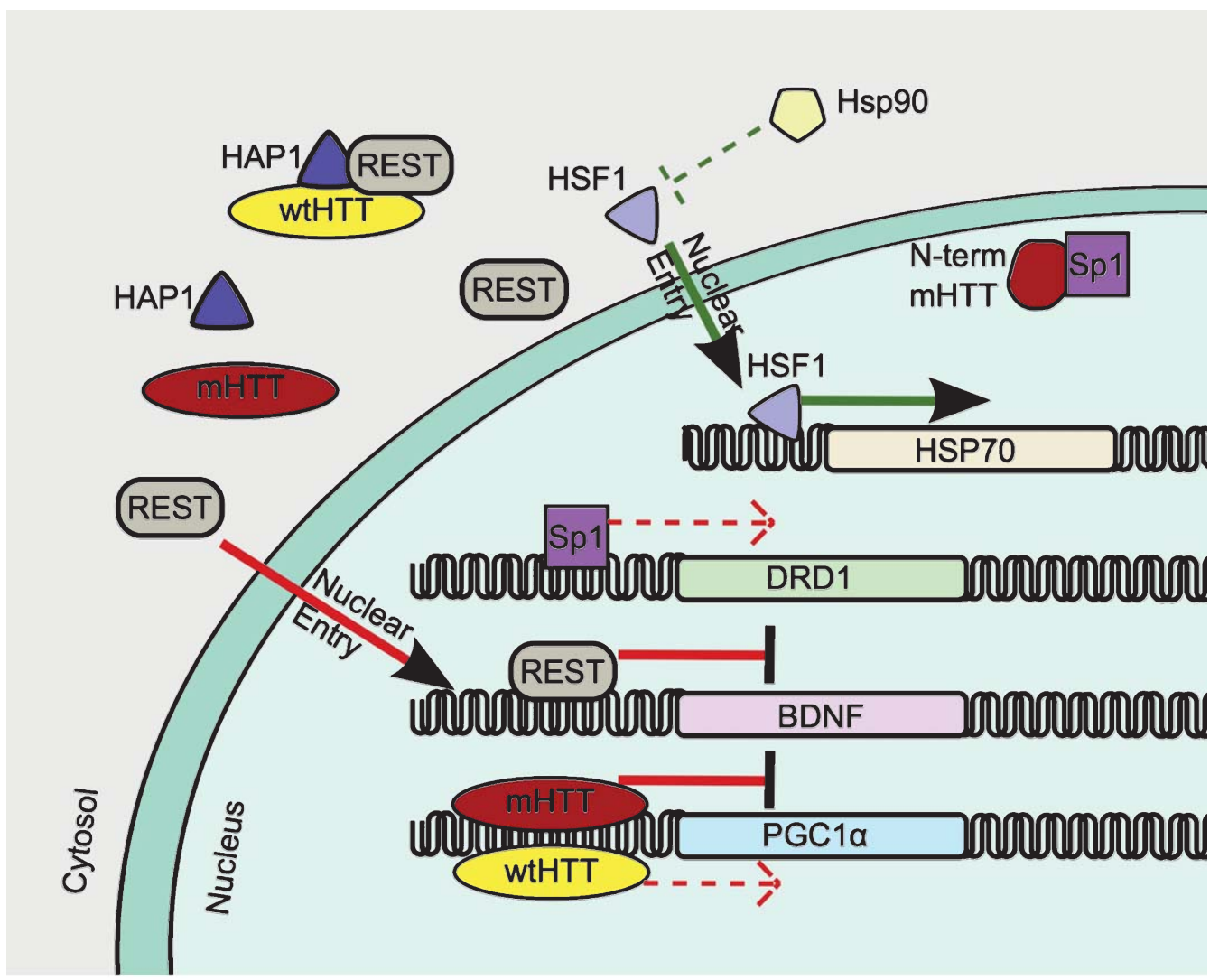

mHTT Effects (Direct or Indirect) on Molecular Processes

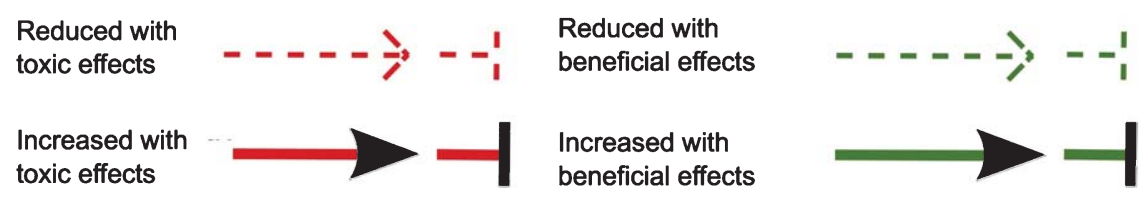

Fig. 3. Transcriptional dysregulation by mHTT. Many classes of genes are dysregulated by mHTT. Genes such as DRD1 have reduced transcription due to sequestration of transcription factor Sp1 by nuclear N-terminal mHTT. BDNF levels are repressed by REST/NRSF, which is normally excluded from the nucleus by a complex including wtHTT and HAP1. mHTT also directly represses PGC1 $\alpha$ (gene name PPARGC1A) expression, a process normally induced by wtHTT. However, the presence of protein folding stress and oxidative stress also cause Hsp90 to release HSF1, allowing it to upregulate heat shock proteins like HSP70.

the REST/NRSF sequestration complex, REST/NRSF now enters the nucleus more freely, reducing the levels of its target neuronal transcripts [63, 64].

Given the large number of transcription factors affected by HTT polyQ expansion, global transcriptional profiles are highly informative. In patient tissues studied by array-based transcriptional profiling, many categories of genes are significantly dysregulated. These include synaptic transmission, neurogenesis, ATP synthesis, CNS development, and $\mathrm{Ca}^{2+}$ transport, among others [65], and similar alterations are present in blood and skeletal muscle samples from patients $[66,67]$. Studies in mouse models gave similar results, indicating that this is a shared and consistent feature of mammalian $m H T T$ expression [68-70]. REST/NRSF targets are of particular interest, based on two lines of study. First, it was determined that those genes that are most strongly downregulated in HD brain are most highly enriched for being targets of REST/NRSF, suggesting that of all of the transcription factors with altered activity in $m H T T$ expressing neurons, REST/NRSF plays a particularly central role (Reviewed in [71]). Second, a particularly crucial gene for striatal health is $B D N F$, which encodes a neurotrophic factor mainly produced in the cortex and trafficked by afferent projections to the 
striatum [72]. There are four alternative promoters for $B D N F$, and it is promoter II that is responsible for most of the physiological BDNF present in the striatum. REST/NRSF controls transcription from this promoter, resulting in significantly reduced levels of this transcript in HD mice and cell models (Reviewed in [73]). REST/NRSF-mediated suppression of $B D N F$ and other transcripts is observed in mice and patient samples [74]. Loss of wtHTT recapitulated some of these effects in embryonic stem cells, and surprisingly, the transcriptional profiles of HD model mice and patient samples are remarkably similar to that of a heterozygous knockout $B D N F$ mouse [70].

Dysregulated REST/NRSF targets (BDNF in particular) are not the only disease-relevant dysregulated genes. As an additional example, PGC1 $\alpha$ (gene name PPARGC1A), a central regulator of mitochondrial biogenesis, activity, and structure, is itself dysregulated in HD. Given striatal cells' particular vulnerability to perturbations of electron transport chain (ETC) function (to be discussed later), this may go a long way to explaining striatal vulnerability in HD. mHTT is found at the PPARGC1A promoter [75], and PGC1 $\alpha$ levels are reduced in striatal but not cortical samples from HD mice [76]. In addition, its loss in wild type animals results in striatal lesions, while its loss in HD mice exacerbates symptoms [75, 77]. Mitochondrial energetic problems in HD are manifold, and will be discussed in more detail later, but reduced levels of PGC1 $\alpha$ only worsen energetic demands on already fragile MSNs.

\section{TAKING OUT THE TRASH: AUTOPHAGY AND mHTT}

For all the focus on transcription and translation in modern molecular biology, it's easy to forget that in general, for every protein produced, another is degraded. In protein folding disorders like HD with impaired degradation of a misfolded toxic protein, this process is clearly deranged, if only subtly.

Proteins are largely degraded either by the proteasome, which typically requires interaction with ubiquitinated substrates that are brought to the proteasome by chaperones, or by the lysosome/autophagosome processes when the protein in question is too large or aggregated to be fed into the proteasome (Fig. 2). It is well known that mHTT is often ubiquitinated, particularly in inclusions, and that chaperones also are readily found in association with it $[9,30]$. There is also evidence that impairment of the proteasome worsens mHTT toxicity [78, 79]; this may be of limited direct relevance, though, as the proteasome is relatively poor at degrading polyQ proteins. The eukaryotic proteasome's three protease activities cut after hydrophobic, basic, and acidic residues, but glutamine fits none of these criteria, and is thus resistant to proteasome-mediated proteolysis [80].

Autophagy, on the other hand, is more amenable to not only degrading polyglutamine-bearing proteins, but at engulfing and disposing of insoluble inclusion bodies (Fig. 2). Cells expressing $m H T T$ seem to detect this protein homeostasis threat and increase autophagy signals, particularly cathepsins [81], and impairment of proteasome function increases autophagy-mediated degradation of mHTT fragments [82]. Increased autophagy through starvation or dietary restriction also reduces the toxic effects of mHTT $[82,83]$.

HTT, being often membrane-associated, is found on autophagosomes (wtHTT, full-length mHTT, and Nterminal mHTT are all seen there) [84, 85]. Targeting to the autophagosome is carefully regulated by acetylation at $\mathrm{K} 444$. This residue is acetylated by CBP and deacetylated by HDAC1, and mutating this residue, preventing acetylation, increases mHTT levels and toxicity in vitro and in vivo [86]. This effect is dependent on macroautophagy (as it is LC3-dependent), which is one of two autophagy pathways relevant to mHTT degradation, the other being chaperone-mediated autophagy. Macroautophagy plays an important role in removal of toxic mHTT, as LC3 knockdown increases the presence of mHTT aggregates. However, macroautophagy is reduced in general in $m H T T$-expressing cells, while chaperone-mediated autophagy seems to try to compensate, as it increases in such cells. This phenomenon may partly explain the late onset nature of the disease, as this LAMP-2 and Hsc70-dependent chaperone-mediated autophagy pathway becomes less effective in aged HdhQ111 mice [87]. Lastly, an essential regulator of autophagy, $A T G 7$, houses a SNP that reduces the age of onset in patients [88], giving autophagy additional credibility as a potential therapeutic target.

\section{mHTT AND MITOCHONDRIA: ALTERED ACTIVITY, MORPHOLOGY, AND PERMEABILITY}

Mitochondrial function has long been a crucial player in HD pathology (Fig. 4), and may be more important to striatal neurons than those of other parts of the brain such as the cortex and cerebellum. Some 


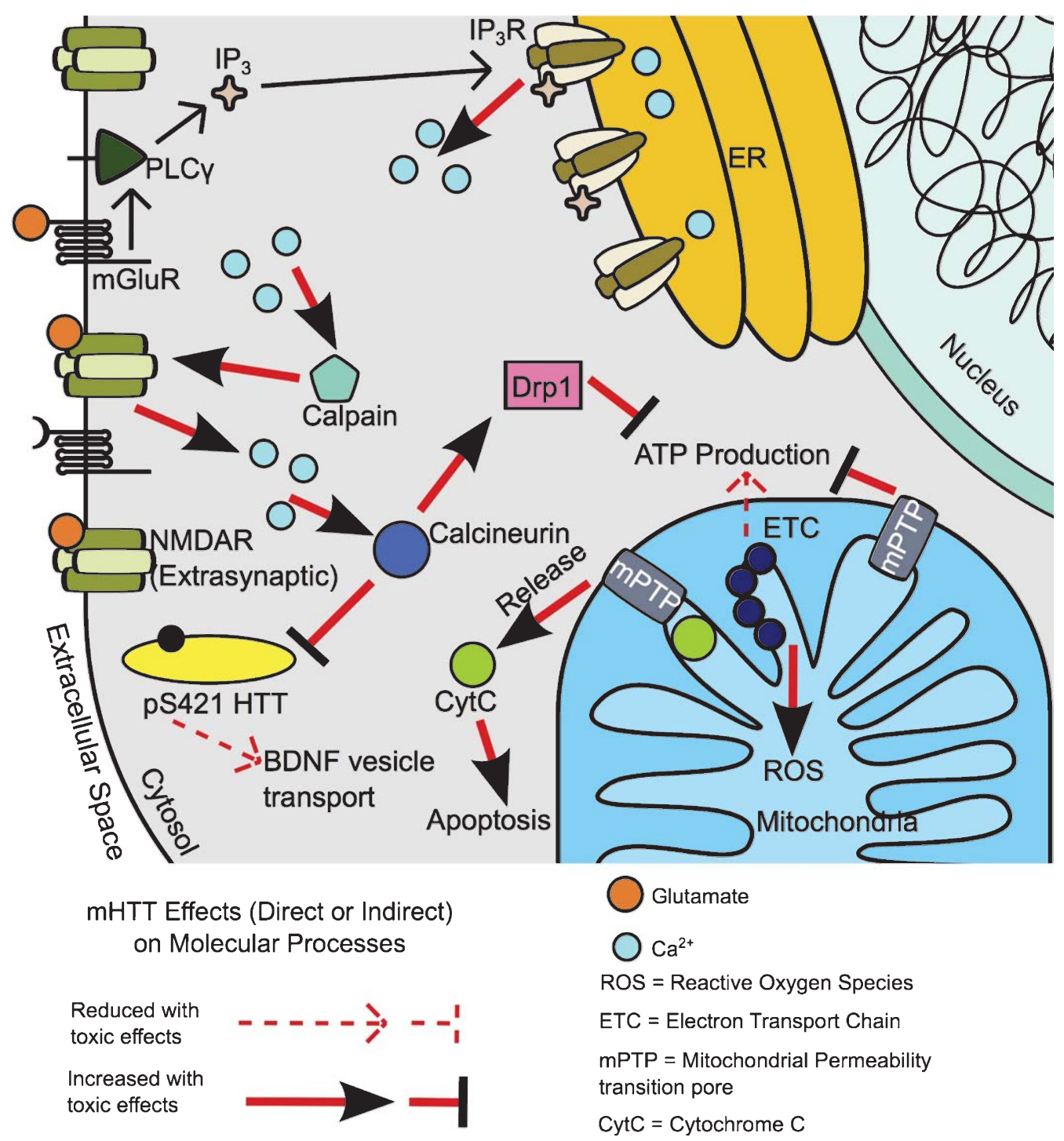

Fig. 4. Glutamate Receptors Cause Calcium-mediated Toxicity in HD. Glutamate activates two classes of receptors, leading to toxicity due to hypersensitive mitochondrial permeability transition pores (mPTPs). mGluRs activate PLC $\gamma$, causing $\mathrm{IP}_{3}$ to allow $\mathrm{IP}_{3}$ receptors on the ER (hypersensitized by mHTT) to release $\mathrm{Ca}^{2+}$ into the cytosol. Meanwhile, extrasynaptic NMDARs open to glutamate, allowing $\mathrm{Ca}^{2+}$ into the cytosol. This increase of $\mathrm{Ca}^{2+}$ leads to many toxic pathways. Calpain activity increases, causing among other things increased extrasynaptic NMDAR presence. The phosphatase calcineurin is also activated, reducing pS421 levels on HTT which hampers the vesicle transport of cargo like BDNF. Calcineurin also activates Drp1, causing mitochondrial fission that hampers ATP production. More directly, $\mathrm{Ca}^{2+}$ causes opening of the mPTP, which has three effects. First, mitochondrial potential drops, reducing ATP production. Second, reactive oxygen species (ROS) production spikes. Third, cytochrome $\mathrm{C}(\mathrm{CytC})$ is released, activating apoptotic pathways.

of the first evidence for this was the demonstration that systemic treatment with 3-nitropropionate (3NP), a specific mitochondrial Complex II (succinate dehydrogenase) inhibitor, induces neurotoxicity that is reminiscent of HD in terms of its cell-type specificity [89]. Intraperitoneal injection of the drug induces striatal lesions (cell death and gliosis) due to death of MSNs but, similarly to brains of HD patients and genetic animal models, the cholinergic interneurons are spared. This made 3-NP treatment a simple, rapid animal and cell model of HD, and its continued study demonstrated further similarities in mitochondrial dysfunction to cells expressing $m H T T$.

3-NP's inhibition of the ETC has many interesting effects, most of which seem to damage MSNs disproportionally. Its overall effects on mitochondrial 
energetics and ATP production play a role, as treatment results in depolarization of MSNs but not HD-resistant interneurons [90]. Energetics don't tell the whole story though, as the effects of 3-NP can be ameliorated without rescuing succinate dehydrogenase. 3-NP-treated samples generate reactive oxygen species (ROS) and produce DNA oxidative damage [91]. Antioxidants and free radical scavengers protect striata from lesions and protein carbonylation [92], so the striatal specificity of 3-NP seems to rely in some part on ROS generation. 3-NP also appears to induce toxicity via sensitization of mitochondrial permability, as inhibitors of the permeability transition pore (PTP) prevent damage in culture $[93,94]$. The effects of disruption of the ETC were also examined genetically when a restriction enzyme (PstI) was directed to the mitochondria in transgenic mice, producing a condition of chronic mitochondrial DNA (mtDNA) damage and reducing ETC activity under careful transcriptional control. In this study, as is the case with 3-NP treatment, MSNs of the striatum are particularly sensitive to mtDNA damage/reduced ETC activity. Additionally, the mitochondria specifically were hypersensitive to challenge with $\mathrm{Ca}^{2+}$ [95], a response that will be covered in more detail in the next section.

Once the HTT gene was cloned and mouse and cell models of $m H T T$ expression were more prominent, studying the interplay between mitochondrial function and mHTT was possible. Based on the 3-NP studies and its demonstrated ability to selectively damage MSNs in an HD-like pattern, patient and cell samples were tested for mitochondrial activity. Striatum from late-stage patients demonstrates reduced activity of multiple complexes of the ETC, and DNA oxidation is also increased [96-98]. The cortex and cerebellum are relatively spared in this regard, suggesting a mechanism of those tissues' relative protection from mHTT. Furthermore, ATP levels (reported as the ATP/ADP ratio) were reduced in lymphoblastoid cell lines generated from patients [99]. Two points are notable from this study. First, there was exquisite CAG-lengthdependence, as the correlation between high repeat length and low ATP/ADP ratio was strikingly strong, and second, there was even a reduction in ATP/ADP ratio in cells expressing $H T T$ with high-wild-type repeats (30-35), a range not known to produce neuropathology.

Mouse models of HD show similar ETC abnormalities. Striatal slices in culture from mice expressing an N-terminal transgene have half of the respiratory capacity of their wild type littermates, though interestingly, this effect was rescued by perfusion with succinate, indicating that in spite of 3-NP's ability to mimic HD, it may not specifically be succinate dehydrogenase that is the defective enzyme in HD striatal cells limiting their respiratory capacity [100]. R6/2 mice, expressing a particularly lethal $m H T T$ transgene, have elevated striatal DNA oxidation and glutathione levels [101, 102], and mHTT primes their mitochondria to depolarize more readily upon exposure to 3-NP [90, 103]. Their sensitivity could be compounded by impaired mtDNA repair, a phenomenon shared between R6/2 mice and 3-NP-treated mice [91]. ETC defects are not limited to mouse neurons in the brain, as immortalized striatal precursors from knockin mice behave similarly to patient-derived lymphoblasts by demonstrating reduced ATP/ADP ratios [104].

Many studies have also demonstrated that mitochondrial morphology and movement are altered in HD samples, and not only is this not a simple byproduct of toxicity, but its prevention can ameliorate toxicity. Initially, it was demonstrated that increased fragmentation and reduced movement are observed in cells expressing $m H T T$ [105], possibly relating to aberrant trafficking to the mitochondria of mHTT [106]. Further studies have revealed aberrant morphology of mitochondria in HD patient lymphoblastoid cells, myoblasts, and fibroblasts [107, 108], effects that are more severe in homozygote samples than heterozygotes. Altered mitochondrial morphology is highly dependent on a subset of genes involved in fission and fusion of the mitochondrial reticulum, and Drpl has been studied in some detail in this regard. Drp1, a mitochondrial GTPase enzyme, positively regulates mitochondrial fission [109]. Drp1 levels are increased in mid- to late-stage HD patient striata $[110,111]$, and its GTPase activity is increased upon interaction with mHTT $[112,113]$. Phosphorylation of Drp1 suppresses its activity, while both the increased basal levels of calcineurin seen in HD (a phosphatase of Drp1 among many targets) and impairment of its phosphorylation by staurosporine increase its activity and resulting mitochondrial fragmentation [114]. This can be rescued by dominant negative (DN) Drpl [109], and in fact, DN Drpl expression in a C. elegans polyQ model partially rescues its motor defect [115].

\section{EXCITOTOXINS AND STRIATAL VULNERABILITY}

The specificity of neurodegeneration in HD (selectively killing the GABAergic MSNs of the striatum 
while cholinergic interneurons are spared) is striking. In trying to explain this pattern, a popular hypothesis is that $m H T T$-expressing MSNs are particularly sensitive to the glutamatergic inputs from the cortex. Glutamate normally activates many receptors, among which are ionotropic NMDA receptors and metabotropic mGluR receptors, which lead either directly or indirectly to increases of intracellular $\mathrm{Ca}^{2+}$ (Fig. 4). An excellent review on calcium's role in neurodegeneration [116] summarizes it thusly: as $\mathrm{Ca}^{2+}$ levels rise in the neuron (from both NMDA receptor influx and from $\mathrm{Ca}^{2+}$ escaping the ER by way of hyperactive $\mathrm{IP}_{3}$ receptors), three things happen. First, calcium-mediated proteases (e.g. calpains) are activated, degrading substrates that can include cytoskeletal components and neurotransmitter receptors. Second, levels of reactive oxygen species rise via perturbations of oxidative phosphorylation. Third, mitochondrial permeability is induced, flooding the cytosol with proapoptotic factors such as cycochrome C. mHTT appears to prime mitochondria for this toxic insult, as mitochondria from HD mouse models (both brain and muscle), patient lymphoblastoid cells, and knockin mouse striatal precursors all permeabilize in response to lower levels of $\mathrm{Ca}^{2+}$ than is seen in wild type samples [117-119]. In all of these cases, mitochondrial permeability transition pore (mPTP) opening not only releases proapoptotic factors but also depolarizes mitochondria, hampering ATP production, and allows glutathione and calcium to escape, exacerbating damage from ROS and cytosolic $\mathrm{Ca}^{2+}$ levels.

The observation that NMDA receptor agonists, many of which are analogs of glutamate, can cause toxicity when administered at highly supraphysiological concentrations (termed "excitotoxicity") [120] led to a great deal of research on how normal excitatory stimuli cause apoptosis when present in excess. One such excitotoxin, kainic acid, specifically lesions the striatum when administered intracranially [121]. Kainic acid is not an endogenous metabolite, unlike quinolinic acid (QA), an excitotoxin that is a product of tryptophan metabolism. When administered intrastriatally to rats, QA's effects, much like those of 3-NP, are strikingly similar to HD (albeit occurring acutely rather than over weeks to years) in that the MSNs are destroyed rapidly but cholinergic interneurons are spared [122, 123]. This effect is not rodent specific, having been demonstrated in primate brains and additionally establishing that NMDA receptor activation mediates the toxicity, as an antagonist prevented the damage [124]. At this point, it was commonly proposed that much of HD pathology stems either a) from endogenous excitotoxic metabolites like QA leading to degeneration of $m H T T$ expressing neurons, or b) because $m H T T$-expressing neurons are hypersensitive to normal glutamate inputs from the cortex.

There is intriguing recent data to suspect the former (endogenous tryptophan metabolites like QA) plays a role. Typically studied by delivery of synthetic QA to the brain, as it is an endogenous metabolite, it has been investigated in animal models whether modulation of steady state tryptophan metabolism may play a role in HD. In fly HD models, administration of 3hydroxykynurenine (3-HK), a precursor of excitotoxic QA, enhances neurodegeneration, while deletion of the enzyme just upstream of 3-HK, kynurenine monooxygenase (KMO), rescues the effect [125]. Furthermore, some benefit to survival and reduction in inflammatory microglial activation were seen in $\mathrm{R} 6 / 2$ mice treated with a specific KMO inhibitor [126].

Much of the HD/excitotoxicity subfield has focused on calcium currents from NMDA receptors (NMDARs). They can be found at the synapse or on the extrasynaptic plasma membrane, where their activation evokes different responses [127], and are heterotetramers composed of two NR1 and two NR2 subunits. NR2 comes in two main subtypes, NR2A and NR2B, and aside from different developmental functions, they appear to elicit different responses to the presence of mHTT. NR2B-containing NMDARs, both synaptic and extrasynaptic, have higher $\mathrm{Ca}^{2+}$ currents in cells expressing mHTT when challenged with chemical agonists or synaptic glutamate [128, 129]. This may be a minor effect on cellular health compared to the sensitized mPTP on mitochondria of $m H T T$-expressing cells $[118,130]$, but increased NR2B levels compound neurodegeneration [131] and are normally found in tissues that are more vulnerable to mHTT [129].

If increased $\mathrm{Ca}^{2+}$ currents are not responsible for excitotoxicity [118], how does NR2B play a role? Subcellular localization and posttranslational modifications of NR2B seem important to the specific response to agonists evoked by their NMDARs. Many studies suggest it is extrasynaptic NMDARs that mediate much of the toxicity from agonism. Synaptic/extrasynaptic localization is regulated by both cleavage of the C-terminus by calpain and dephosphorylation by the phosphatase STEP, both of which reduce its synaptic presence [132]. This may alter the balance of downstream CREB-mediated transcription pathways, which are activated by synaptic NR2B NMDARs but inhibited by the extrasynaptic ones. [133]. Extrasynaptic NR2B-containing NMDARs are more common in HD mice, possibly in part because 
both STEP and calpain levels are increased in $m H T T$ expressing animals $[132,134,135]$.

Given the relationship between mHTT and NMDAR activity and locations, many HD model mouse strains have been tested for their response to excitotoxic stimulus, generally via intrastriatal injection of kainic acid or quinolinic acid. The particulars of each strain's response to such stresses are reviewed elsewhere [134, 136, 137], but a basic trend is apparent, and the correlation involves mHTT aggregation. As was previously discussed, it is still unclear what role aggregates play in disease, and it is likely that visible aggregates have little to no role in disease other than as a histological byproduct of polyglutamine stress. However, over many studies, it seems that the appearance of aggregates (but not necessarily visible behavioral symptoms) correlates with a transition from mouse models being hypersensitive to excitotoxicity to being resistant to such insults. While cells with mHTT aggregates are not necessarily as healthy as cells only expressing wtHTT, it seems clear that aggregation is a sign of a cellular attempt to cope with such stress. Both visible aggregation and survival of cells expressing polyQ proteins are influenced by chaperone proteins like Hsp40, Hsp70, and Hsp90, and mice challenged with the mitochondrial toxin 3-NP suffer less damage when overexpressing Hsp70 [91, 136]. Given that a) 3-NP and other electron transport chain inhibitors generate prodigious oxidative stress $[91,124]$, b) excitotoxins largely kill cells through the $\mathrm{Ca}^{2+}$ influx from NMDA receptors [93, 118, 124], c) neuronal death from both ETC poisoning and excitotoxic stress can be reduced significantly by inhibiting mitochondrial permeability [26, 28, 93, 118], and d) cells and mice that are better capable of promoting aggregation of mHTT survive longer in general [26, 28, 138], one can imagine the following path to resistance to excitotoxicity.

- Initially, expression of $m H T T$ causes reorganization of NMDAR location, activity, and NR2B/NR2A ratios. This puts neurons under steady state $\mathrm{Ca}^{2+}$ elevation, or at least puts them at risk of mitochondrial permeability transition due to mHTT's effect on its sensitivity. Under these conditions (elevated $\mathrm{Ca}^{2+}$ and/or mPTP opening sensitivity), $m H T T$-expressing neurons are subject to oxidative stress.

- Increased oxidative stress leads to general protein homeostasis defects [138, 139], and over time, Hsps are recruited, promoting aggregation of mHTT along the way. This could be aided by a steady-state increase of pro-survival
Akt signaling (which can induce HSF1) [139, 140], since NMDAR-dependent Akt activation has been demonstrated in cultured knockin $m H T T$ expressing cells [26, 140-142].

- When such neurons are later subject to excitotoxicity, they are better equipped to handle acute mitochondrial oxidative stress. Hence, they are resistant to excitotoxicity. wtHTT-expressing cells, on the other hand, have no such steady-state elevation in acute oxidative stress response and are normally vulnerable. Meanwhile, cells with mHTT but which are incapable of generating aggregates instead have tremendous amounts of toxic oligomers, which prime mitochondria for permeability under lower $\mathrm{Ca}^{2+}$ levels but without an elevated proteostasis response, hence rendering them hypersensitive to excitotoxicity.

Excitotoxicity, despite being an artificial condition, can also inform us about mHTT modifications that may be relevant to steady state conditions. We know that increased levels of non-toxic HTT render cells resistant to excitotoxicity [26, 141-143], which in the context of excitotoxins' mitochondrial-mediated toxicity, lends importance to the fact that many proteins involved in mitochondrial function bind with HTT [142-144]. We use the phrase "non-toxic HTT", because in this case, we also mean mHTT that does not cause toxicity, evidenced by caspase-6-resistant (C6R) mHTT (a strain carrying a version of mHTT that is resistant to caspase6 cleavage, limiting the production of $\mathrm{N}$-terminal fragments) and the previously-mentioned Shortstop (Ss) strain, both of which have an expanded polyQ tract but neither of which induces neurodegeneration in vivo or in vitro when expressed from an endogenous human HTT promoter [28, 142, 144]. Because C6R mHTT has reduced production of toxic $\mathrm{N}$-terminal fragments while Ss mHTT appears to aggregate too readily for toxic oligomers to occupy a significant population in this strain [28, 145], it seems all the more apparent that mHTT fragment oligomers, but not full length mHTT or aggregated mHTT, are what render mitochondria hypersensitive to $\mathrm{Ca}^{2+}$ fluctuations. Such $\mathrm{Ca}^{2+}$ fluctuations likely occur in the absence of excitotoxicity and are carried out by corticostriatal glutamatergic inputs, because decortication relieves some neurodegeneration in R6/2 mice [145-147].

Excitotoxic stimulation also informs us about the steady state phosphorylation dynamics of certain disease-relevant residues within HTT. One such residue, serine 421 (S421) has been studied in detail and its phosphorylation influences vesicle transport 


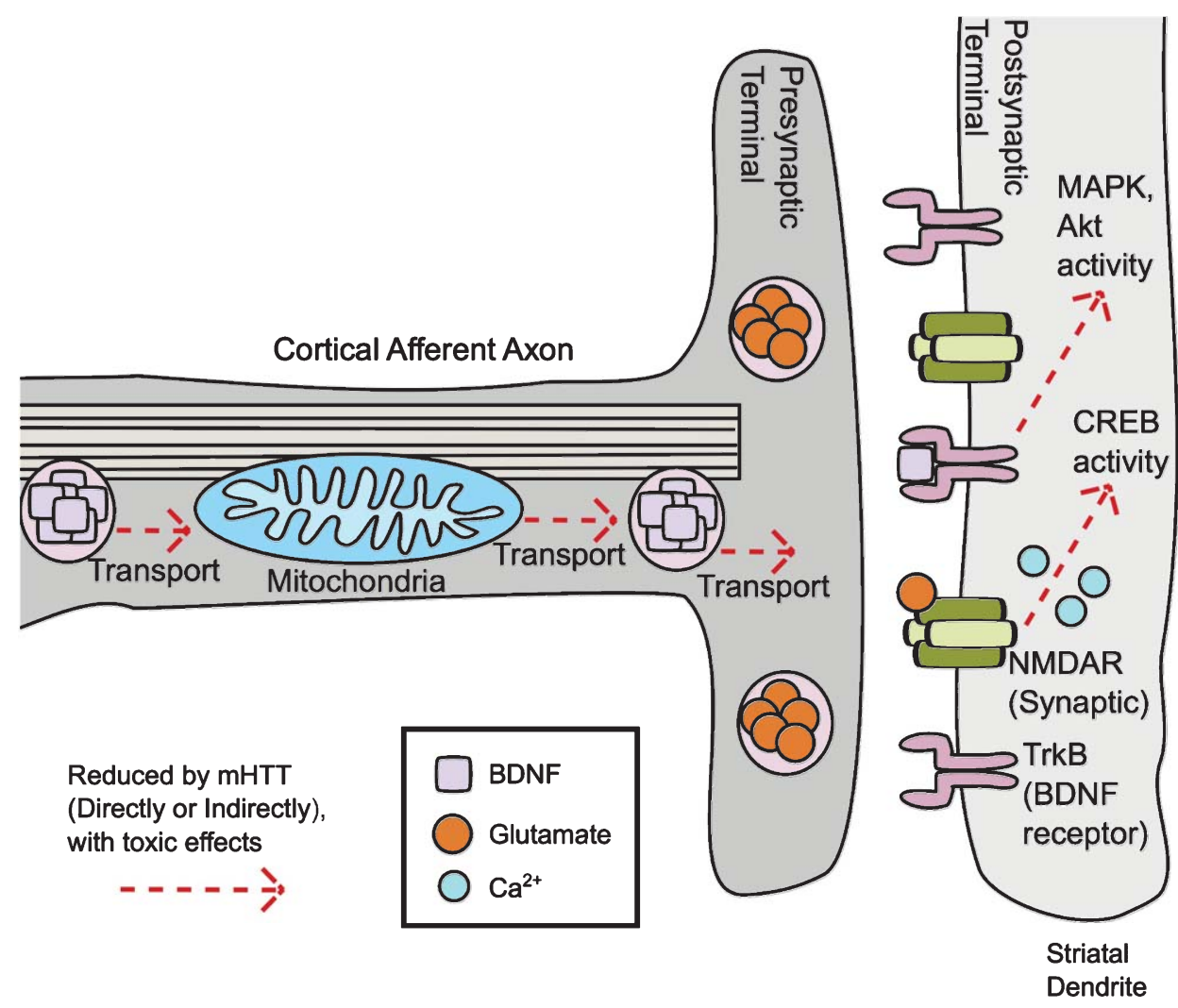

Fig. 5. Toxicity at the Synapse. mHTT impairs transport down the axon towards the synapse. Mitochondria are not efficiently trafficked, impairing energetics at the synapse. BDNF also is not efficiently transported, so postsynaptic TrkB receptors less efficiently activate prosurvival MAPK and Akt pathways. Additionally, mHTT results in fewer synaptic NMDARs, so prosurvival CREB activity (specifically the result of synaptic $\mathrm{Ca}^{2+}$ influx) is reduced.

(discussed in the next section). S421 phosphorylation is reduced after excitotoxic stimulation, and is also seen in YAC128 transgenic mice [146-148]. The likely culprits are the phosphatases calcineurin and PP1, which have altered activity in $m H T T$-expressing cells. Calcineurin levels and activity are elevated, directly or indirectly, by mHTT [147, 148]. Meanwhile, PP1 is inhibited by activity at the dopamine D1 receptor, whose levels drop over time in HD patients and model mice [147, 149-152]. As phosphorylated S421 is well known to reduce mHTT toxicity [149-152], it is clear that excitotoxic stimuli are also acting direcly on HTT (rather than solely on mitochondrial permeability) to contribute to neurodegeneration.

\section{BDNF TRANSPORT ALTERATIONS AND STRIATAL VULNERABILITY}

While we see that phosphorylation of mHTT S421 rescues cells from excitotoxicity, it also modulates a vesicle trafficking defect seen in HD cortical neurons [149, 151] (Fig. 5). These vesicles are carried by the dynactin/microtubule network via a complex involving HTT, HAP1, and p150 $0^{\text {glued }}$. This requires HTT S421 phosphorylation for proper directional movement along the microtubule network [72, 151, 153]. A major cargo delivered by these vesicles is BDNF. Striatal degeneration is seen in Bdnf knockout mice, while its overexpression reduces neuropathology in YAC128 HD model mice [72, 153, 154]. Its altered transcript levels clearly play a role in pathology, but even if transcribed properly, it must be efficiently delivered to the striatum from its site of production in the cortex. Calcineurin-regulated dephosphorylation of phosphoS421 is an attractive target, and inhibition of calcineurin by FK506 rescues phosphoS421 levels and BDNF vesicle transport in vitro [154]. Delivery of exogenous BDNF may go a long way towards therapy in $\mathrm{HD}$, and it has been demonstrated to be beneficial in model mice with many delivery modes $[1-3,153$, 155-157]. 


\section{FROM TARGETS TO THERAPEUTICS: IDENTIFYING AND TESTING CANDIDATE INTERVENTIONS}

There are no validated neuroprotective therapies for Huntington's Disease, but if the previous sections are any indication, we understand a great deal about the pathways leading to neuropathology. For the last 10 years, it has been fairly well known that rescuing mitochondrial energetics, reducing corticostriatal glutamate signaling, scavenging free radicals, normalizing protein homeostasis, or reversing transcriptional dysregulation at a single-transcript (e.g. $B D N F$ ) or global level could eventually be viable options for therapeutic intervention. The crux of the issue, now, is not just continuing to identify new targets, but also sifting through the potential interventions, whether drug or otherwise, and evaluating their efficacy in patients. The slow course of the disease may be preferable for patients when contrasted with a rapid, deadly neurodegenerative disorder like Amyotrophic Lateral Sclerosis. However, the slow and steady nature of HD also makes conclusive determination of a candidate therapeutic's ability to alter disease progression very difficult.

\section{DIAGNOSING HD AND MEASURING ITS PROGRESS}

HD's progressive nature makes it possible to quantify the degree to which the disease is impairing neural pathways or social functions. The Unified Huntington's Disease Rating Scale (UHDRS) was developed in the mid 1990's to attempt to standardize diagnostic parameters across many sites and as performed by different investigators [158]. With an eye on clinical trial facilitation, it places an emphasis on those symptoms which advance most rapidly but all of which can ideally be evaluated within a 30 minute period. The UHDRS divides symptoms into four categories: 1) Motor symptoms, including oculomotor, dysarthria, chorea, dystonia, gait, and posture. 2) Cognitive symptoms, including phonetic verbal fluency, symbol digit modalities, and the Stroop word test. 3) Behavioral Assessment, organized into subscales of mood, behavior, psychosis, and obsessiveness. 4) Functional capacity, a questionnaire covering a wide range of functional impediment, from the subtle to the highly disruptive.

Nearly every HD Phase II or III clinical trial since the mid-1990's has used this or a subsection of this as a primary endpoint, often Motor Score or Total Functional Capacity, as worsening scores in these categories are highly associated with patients' quality of life decline. While it is clear that improvement in these real-life behavioral derangements is the overall goal for patients, many of these are by their very nature subjective and variable. A patient may be more likely to be depressed if a family member died, or more irritable after an argument with his or her spouse, or have better chorea depending on the time of day. Efforts can be made to normalize and reduce variability in these, but it is well appreciated that other measurement tools, not subject to day-to-day randomness or bias, can augment the evaluation of disease progression. This is not just essential for drug rescue measurements, but for giving accurate assessments of whether a patient's acute worsening is likely a "bad day" at the test, or a sign that a change in his or her medical care is in order.

The field has made advancements in disease progress measurement in two main areas: brain volumetric or activity imaging, and peripheral biomarker discovery. Imaging is the area with the most precision at the moment, though its high cost and the challenges of standardizing techniques center-to-center remain to be solved. Soon after postmortem tissue evaluation detected loss in neurotransmitter receptor levels, Positron Emission Tomography (PET) was used in living patients. Using specific ligands for dopamine D1 and $\mathrm{D} 2$ receptors, it was determined that binding of these ligands sharply decreases in patients [159]. Furthermore, D2 receptor signal loss was found to agree almost perfectly with postmortem tissue analysis in a specific way: $35.5 \mathrm{CAG}$ repeats represent a clinical threshold of sorts, wherein any increase of repeats past 35.5 presents a proportionally increased rate of cell loss, pathological grade advancement, and D2 receptor binding loss $[160,161]$. In other words, a patient with 48 repeats ( 12.5 over the threshold) at age 60 will have lost roughly twice as many neurons and twice as much D2 binding as a 60 year old patient with 42 repeats ( 6.5 over the threshold).

Given what we know about the specificity of degeneration, it is no surprise that progression can be followed by MRI volumetric measurements. There is a wealth of knowledge in this regard, and many studies have been focused on presymptomatic individuals (to be discussed in more detail later), but in general, the common sites for measureable changes are the striatum (both caudate nucleus and putamen), globus pallidus, nucleus accumbens, and cortical white matter $[162,163]$. Loss of volume or neuronal numbers in other regions, such as the thalamus, hypothalamus, 
hippocampus, and other subcortical structures are commonly observed in patient samples and mouse models and can alter non-motor pathways such as the hypothalamic-pituitary-adrenal axis [164-169]. However, because motor and cognitive symptoms are ubiquitously used as primary outcome measure in clinical trials, those structures whose degeneration correlates most closely with these measures (the striatum and cerebral cortex) are best studied. This regional degeneration is not uniform patient-to-patient, particularly in the cortex, and this variation is likely to underlie and explain at least a portion of symptom variability from patient to patient. Through careful postmortem stereology, it was determined that patients with strong motor symptoms consistently demonstrate more cell loss in the primary motor cortex, whereas cell loss in the anterior cingulate cortex was strongly associated with mood dysfunction [170]. Such information could help stratify patients in clinical trials to improve the power of trials that use volumetric MRI as an endpoint. Volumetric analysis is not the only use of MRI technology with practical applications to HD. Another useful technology is functional MRI, which measures the uptake of glucose molecules radiolabeled to emit positrons, which are visible to MRI. As neurons take up glucose in proportion to their rate of action potential firing, such images can be taken during tasks to measure brain activity (or lack thereof). In one such study, caudate and putamen activities were seen to rapidly decline in HD patients, with slower declines seen in many cortical structures [171].

MRI is powerful, but due to its high cost and the necessity of bringing patients to the testing centers, peripheral biomarkers of disease progression are sorely needed. There is some progress in this regard, as blood can be collected easily and HD patient samples have already demonstrated differences in a subset of transcripts [66] as well as creatine kinase levels [172]. Gene-positive individuals have also demonstrated increases in oxidative damage markers, namely 8-OHdG DNA [173] and lipid peroxidation [174]. The former may not have robust utility [175], but lipid peroxidation correlated well with patients' UHDRS motor scores and independence scales. Remarkably, mHTT itself can be measured in patient leukocytes, using a highly quantitative fluorescence assay [176]. This may be particularly useful if an attempt is made to knock down HTT levels systemically using oligonucleotide therapeutic approaches. Muscle biopsies have also been analyzed by transcriptomics, and there are at least 100 transcripts showing strong changes between patients and controls [67]. More studies are needed to arrive at a workable group of tests to assess progression with minimal invasiveness, but the progress so far is encouraging.

\section{PATHOLOGY BEFORE PHENOCONVERSION: PREMANIFEST HD}

As demonstrated by MRI and postmortem studies, significant tissue damage and neuronal loss is apparent even early in manifest disease $[162,163]$. However, the HD community is in the unique position of being able to conclusively identify individuals who, assuming no accidents occur, will eventually get the disease. Of course, many individuals at risk for HD (those with an affected parent) choose not to be genotyped, an understandable decision given the future implications that such a genetic diagnosis carries $[177,178]$. Nevertheless, populations of such genotyped individuals allow for a wealth of research into the dysfunctions prior to visible symptoms. Just as importantly, clinicians can use premanifest populations for the development of neuroprotective therapeutics with the hope of forestalling or preventing pathology altogether. As an aside, nomenclature in these studies is not uniform when referring to individuals with the mutation but who do not yet have conclusively-diagnosed HD. So, despite their subtle differences in the medical literature, for clarity, "presymptomatic", "asymptomatic", "prodromal", and "premanifest" will all be referred to as premanifest when discussing the below studies.

All of the above diagnostic tools have been brought to bear to monitor the progression of neuropathology in premanifest populations, revealing some interesting clues to the disease process. Several early studies using PET ligands for dopamine receptor D2 demonstrate loss of signal in premanifest patients $[58,161$, 179, 180]. This loss of signal may be attributable to the loss of caudate and putamen volume in premanifest patients [181], but it likely isn't that simple. The transcription factor $\mathrm{Sp} 1$ is partly responsible for control of dopamine receptor D2 (DRD2) transcription, and its binding to the transcriptional coactivator TAFII130 is weaker in both manifest and premanifest brain tissue samples [182], so transcriptional dysregulation is likely also occurring very early in pathology. The presence of blood mRNA biomarker elevations in premanifest patient samples supports this [66].

Structurally, many of the alterations observed in manifest HD are present in a lesser form in premanifest HD. Studies have demonstrated reductions in the volumes of the whole brain, striatum, cortical white 
matter, and globus pallidus, with an expected increase in the size of lateral ventricles [181, 183-187]. Most of these changes are progressive, and tracking these changes longitudinally within a patient will allow clinicians to have a better idea of whether their interventions are having a beneficial effect on halting pathology. However, even measurements taken in single visits for premanifest patients are informative. It was demonstrated that both ${ }^{18}$ F-FDG uptake and the ratio of striatal to total brain volume can be used to augment standard predictive measures (CAG repeat length and age) to more accurately predict the age of onset for patients $[186,188]$. This may allow patients to better plan for future medical care. Additionally, it can help clinicians to further stratify premanifest patients in clinical trials into those who are, or are not, expected to phenoconvert (progress from premanifest to manifest) during the trial or follow up period.

Brain activity changes and structural alterations in the premanifest period may come as no surprise, as a late onset, slowly-progressive disease like HD is not going to demonstrate its characteristic degenerative pattern overnight. However, there are also many behavioral symptoms that appear in patients not yet diagnosed with HD. This may seem counterintuitive, but it's worth remembering that an HD diagnosis does not necessitate just any neurological or neuropsychological impairment often present in HD patients. It requires that the neurologist can be certain that this patient has HD, based on the presence of many HD-like behavioral, psychological, and motor manifestations (as laid out in the UHDRS). This array of symptoms is clearly not going to appear all at once. With this in mind, the behavioral alterations present in premanifest individuals have some patterns. Almost by definition, total functional capacity scores are rarely worsened in premanifest patients, but motor, cognitive, and behavioral alterations are commonly observed and worsen as patients approach the expected age of onset $[181,189]$. These commonly include bradykinesia (specifically, finger tapping impairment), impaired circle drawing, poor performance at smell tests, and failures of emotion recognition [183, 187, 190-192]. Detailed analyses demonstrate that word learning and smell tests begin to decline $\sim 15$ years before diagnosis, while motor scores like tapping don't decline until $\sim 10$ years before diagnosis [193]. This seems to add detail to the pattern of cortical white matter degeneration apparent in premanifest patients. Not surprisingly, these behavioral changes are often subtle, and it still appears that volumetric changes of premanifest patients are more quantitative and statisti- cally significant than most UHDRS tests [183]. Some metrics may be more useful than others, though, and tapping, being highly quantitative in nature, might be the best candidate, as it correlates well with striatal and cortical volumetric changes [191].

Such tools to measure premanifest disease progression are of great use to clinicians in trials, but they are still highly variable in this population. This is hardly a criticism, as clinicians don't have the advantage of agematched, inbred populations used in preclinical trials. Nevertheless, many clinical trials likely fail simply due to small sample size, and this is an even greater issue when assessing the power of the subtle premanifest changes. Various studies using volumetric imaging or behavioral alterations, even those of a highly quantitative nature, still estimate sample sizes of approximately 100-350 premanifest individuals would be needed to reliably detect a disease-altering effect of $20-50 \%$, which would be a substantial alteration [184, 187, 194]. Such clinical trials are often difficult to organize for a rare disorder, particularly one whose premanifest population often chooses not to be tested. Therefore, this places particular emphasis on the efficient culling of ineffective candidate therapeutics in the preclinical setting.

In spite of the difficulties in organizing and funding trials that often take a minimum of 1-2 years for confident "go/no go" assessment, there is a tremendous potential market for an HD treatment. Estimates for the market for such a treatment [195], in the US alone, may conservatively assume a patient population of 30,000 with diagnosed HD, and another 170,000 individuals who may elect to take the drug because they are at risk or have a related disorder. In the case of this population, and assuming a conservative estimate of $\$ 15$ per day for drug costs, the potential market exceeds $\$ 1$ billion per year even before accounting for increased survival, such as was seen for patients with chronic myelogenous leukemia taking Gleevec. Combined with the similarities between the cellular and molecular pathogenesis of HD and many more common neurodegenerative diseases, it is easy to see why there is not only a medical need for a treatment, but a commercial motivation for one as well.

\section{THE CURRENT THERAPEUTIC LANDSCAPE: SMALL MOLECULES, SMALL EFFECTS}

Therapeutics for HD (and for neurodegenerative diseases in general) are generally classified into either 
symptom management or disease modifying drugs, the latter of which can be further differentiated into neuroprotective (preventing neurons from being damaged) or neurorestorative (either promoting the regrowth of neurons or strengthening the pathways crippled by the absence of the degenerated connections) [196, 197]. The neuroprotective vs. neurorestorative distinctions are important in the context of patient populations. Premanifest individuals can benefit from both neuroprotection and neurorestoration. However, given the degree of degeneration that has occurred by symptom onset in manifest patients [198], neurorestorative strategies may prove more effective than neuroprotective therapies in such individuals. At this point, there are no approved disease-modifying therapeutics for patients. Symptom management has improved, but thus far, no drugs given to patients extend life expectancy.

After diagnosis, patient therapies are highly individualized. They often include antichoreics, of which tetrabenazine (TBZ) has become the most popular choice and is the only FDA approved drug for HD chorea. However, it has some unfortunate side effects, commonly including depression, drowsiness, fatigue, and parkinsonism [199-201]. A depressive effect is not surprising from a drug with a dopamine depleting function (TBZ inhibits VMAT2, the transporter that loads dopamine into presynaptic vesicles) [202, 203], but given that depression is already a common psychiatric symptom for HD patients, an alternative antichoreic without these side effects would be preferred. Pridopidine is a putative dopamine stabilizer that may serve such a purpose, as a relatively small clinical trial in HD patients demonstrated trends toward improvement of both voluntary and involuntary movement [204]. Importantly, it had no significant side effects, and larger clinical trials are ongoing. Other symptom management interventions include SSRIs for depression, atypical neuroleptics for psychosis, and benzodiazepines for anxiety [196, 205]. Nonpharmaceutical therapies are also crucial for patient care, particularly as patients lose independence in late stage disease [206]. This includes physical therapy, occupational therapy, speech therapy (including swallowing training), and even simple exercise, all of which can improve quality of life in all of the disease stages.

Symptom management is necessary and helpful, but there are also many potential disease-modifying therapeutics already in the clinical pipeline. Those that have made the most progress concern the pathway that was perhaps earliest connected to $\mathrm{HD}$, that of mitochondrial dysfunction. Creatine and coenzyme Q10 (CoQ10) both restore mitochondrial function as antioxidants and also aid energy production through oxidative phosphorylation, and are furthest along in clinical trials. Creatine is well tolerated in doses up to $10 \mathrm{~g} /$ day but showed no benefit to symptoms after up to 2 years of treatment [207-209] other than a reduction of serum 8-OHdG levels [210], a readout whose significance has been challenged [175]. However, there is reason to believe that higher dosing may be required, as the mouse trials on which these were founded supplemented the mouse chow with as much as $2 \%$ creatine. This would correspond to $\sim 25 \mathrm{~g}$ for a patient that eats $1.25 \mathrm{~kg} /$ day. Hence, there are two ongoing large clinical trials with higher doses of creatine, one in manifest HD (CREST-E), and another in premanifest HD (PreCREST) both of which dose up to 30 or $40 \mathrm{~g}$ /day of creatine.

CoQ10 has a similar history. Early clinical trials demonstrated no benefit [211, 212], but the dose was on the low side $(600 \mathrm{mg} /$ day $)$. Upon successful dose escalation trials to demonstrate peak tolerability at $2400 \mathrm{mg} /$ day without adverse events [213], two trials are ongoing at this higher dose. As with creatine, one targets manifest HD (2CARE) and another premanifest HD (PREQUEL), the latter of which is mainly assessing safety and tolerability at this point. Creatine and CoQ10 are also among the few items in clinical trials available as over the counter supplements, another being highly unsaturated fatty acids. A clinical trial has been completed with only a trend towards benefit in the UHDRS motor scale and total functional capacity $(P=0.08$ for each), but most interestingly, there seemed to be not just a halting of progression but an improvement [214]. This may warrant more testing as a potential neurorestorative therapy.

Cystamine and its redox partner cysteamine (upon administration, they rapidly interconvert) are another pair of antioxidants with strong interest from the HD clinical community. Like creatine and CoQ10, they are present in tissues already and represent little risk in high doses, having been given at up to $20 \mathrm{~g} /$ day [215]. Originally thought to function through transglutaminase inhibition but now found to primarily protect neurons as an antioxidant, cysteamine is fairly effective in mouse trials (10-20\% enhanced lifespan, reduced weight loss and motor phenotypes, and less striatal degeneration) [216-218], and a Phase II clinical trial is ongoing in France (CYST-HD).

Given that mHTT's toxicity is mediated at least partially (if not entirely) by altered protein folding, efforts to facilitate its refolding or degradation are ongoing. As 
discussed previously, the upregulation of heat shock proteins has therapeutic potential. While no specific HD trials have been completed, low doses of the Hsp90 inhibitors geldanamycin or 17-AAG have been tested in many cell and animal models of polyQ diseases with promising results $[219,220]$. They have been shown to both alter Hsp90 client protein proteasomal targeting and to disrupt Hsp90/HSF1 binding, which releases HSF1 to the nucleus for induction of Hsps like Hsp70 and Hsp40 [221-223]. 17-AAG doesn't cross the blood brain barrier efficiently, but other Hsp90 inhibitors with similar mechanisms of action are in the pipeline. Ganetespib, currently in clinical trials for some cancers, is more lipophilic and less toxic than 17-AAG [224]. Additionally, a novel Hsp90-inhibiting compound called AT13387 has very long lasting effects, and an interesting (if somewhat disconcerting) side effect of blurred vision with light flashes may be indicative of CNS penetrance [52, 225].

Some other disease-modifying therapeutics are not as far along or have been demonstrated ineffective. Autophagy augmentation through mTOR inhibition has promise, but may require more specificity of action. For example, a rapamycin analog everolimus has good pharmacokinetics, but was ineffective in R6/2 mice [226]. This may be because mTOR has two main downstream pathways, and rapamycin analogs target mTORC1 but not mTORC2, the latter of which has more efficacy at reducing aggregated mHTT proteins in cells [82]. Minocycline was enthusiastically studied 10 years ago and reduces cytochrome $\mathrm{C}$ release from mitochondria in HD models [227, 228]. In mice, the results were conflicting [229-231], and a futility trial in HD patients demonstrated no efficacy and suggested halting its study for HD [232]. A DNA-binding compound mithramycin seems to rescue histone $\mathrm{H} 3 \mathrm{~K} 9$ hypermethylation and rescues pathology in R6/2 mice [233], but has not made it to clinical trials, possibly because it has demonstrated transcription factor Sp1 inhibition [234], so there may be worry of worsening an already present phenotype.

The pleiotropic effects of mHTT on transcriptional profiles, primarily downregulation of neuroprotective genes, have led to investigation of histone deacetylase (HDAC) inhibitors, which might globally relieve this transcriptional repression. Many have therapeutic potential in mouse models (Reviewed in [235]). Sodium phenylbutyrate is one such HDAC inhibitor of interest in HD. It has minimal adverse effects, and a 16-week safety and tolerability trial in HD has been completed, with the results yet to be published (PHEND-HD). The potential of HDAC inhibitors to reverse the global transcriptional dysregulation seen in HD is tempered by the fact that they would be quite likely to have significant adverse effects in patients if treated at high doses, as has been demonstrated in mice alongside neuroprotective benefit [236-238]. Because there are many different histone deacetylases, a targeted pharmaceutical approach may be warranted. With that in mind, strides are being made to identify the particular HDACs whose modulation is most likely to have therapeutic impact [239-241], with the hope that specific inhibitors to those HDACs could be developed with reduced adverse effects and improved efficacy.

Neurotransmitter modulation aimed at neuroprotection has also been attempted, with little success so far. Memantine, an NMDAR antagonist, demonstrated a trend towards motor rescue, but the trial was small [242]. Riluzole, a glutamate antagonist with a somewhat unknown mechanism of action, has been tested numerous times in animals, with demonstrated protection against mitochondrial toxins and excitotoxicity [243-245]. However, its trial was halted in patients due to liver enzyme elevation, despite a benefit for patients in total chorea score and UHDRS motor score [246].

Based on these and other clinical and preclinical studies, there is clearly no shortage of targets in deranged HD pathways for small molecule therapeutics. At this point, the motivation at the bench needs to be generating compounds with safe toxicity profiles that effectively target these pathways, and using available models to more efficiently weed out ineffective drugs or subtherapeutic dosing regimes. The latter is perhaps hardest to predict from preclinical trials, given the differences in pharmacokinetic properties between rodents and humans (primates are simply too expensive to be a standard in-between step, but novel ovine and porcine models are a promising step-up) (Reviewed in [247]). Alternative strategies using cell, gene, or oligonucleotide therapeutics are younger in their development, but as they are more targeted than most small molecules (e.g. delivery of a growth factor rather than a drug that could upregulate many genes, including the desired growth factor), they may provide better predictability in the transition from bench to bedside.

\section{CELL GRAFTING FOR TISSUE REPLACEMENT OR TROPHIC FACTOR SUPPLEMENTATION}

One of the main impediments of small molecule therapeutics is the blood brain barrier (BBB), a 
specialized membrane surrounding blood vessels in the CNS that gives an extra layer of protection from the likes of blood borne pathogens and hyperactive immune insults, among others. However, this also limits the passage of potential therapeutic small molecules or proteins. Without a doubt, patients would tolerate continuous intracranial dosage if such an intervention promised significant improvements in longevity and quality of life compared to current treatment options. Nevertheless, cerebral pump implantation and maintenance is fraught with risks of infection. To avoid this problem, cell and gene therapies that only require single dose implantations to bypass the BBB are being rigorously investigated.

Cell implantation first began as a simple neuronal replacement strategy with the hope that implanted fetal neuronal precursor cells would differentiate into neurons and become useful parts of the corticostriatal network, restoring motor control to patients. Several small patient cohorts have been tested, with varying degrees of success [248-253]. While cell growth is often shown and proper nigrostriatal dopaminergic connections can occasionally be seen, in general the results are only an occasional benefit to the patients' motor scores or total functional capacity. Immunosuppression is often needed, which can lead to infections. It may be possible to get around this using modern induced pluripotent stem cell (iPSC) technology, where it has been demonstrated that patient fibroblasts can not only be reprogrammed into transplantable MSN-like cells [254], but that the cells can be genetically corrected beforehand [255]. In such grafts in patients, though, rejection is likely not the cause for failure. As reviewed in Cicchetti et al., 2011 [256], which discusses the fetal grafting clinical history in HD and Parkinson's Disease, the likely reason for such failures is the death of the engrafted cells, probably as a result of poor trophic support. This makes sense in the context of the hampered delivery of neurotrophic factors from cortex to striatum that plays a well-established role in HD neuropathology.

Hence, for HD and other neurodegenerative diseases, the delivery of such growth factors by way of transduced cells has been rigorously investigated. Many such growth factors may be therapeutic in HD; in 3-NP-treated rats, fibroblasts expressing the factors $B D N F$, neurotrophin-3 (NT-3), neurturin $(N T N)$, or $G D N F$ all suppressed neurotoxicity [257]. BDNF has perhaps been the best studied in this context, as it has demonstrated protective efficacy in toxin and genetic models, via cell delivery methods including mesenchymal stem cells, fibroblasts, and bone-marrow stem cells
[258-265]. Among these varied studies, two are of particular interest. Astrocytes often become activated in HD patients and animal models, as demonstrated by increased presence in the tissue and elevated GFAP expression. These astrocytes, when altered to express $B D N F$ under the control of the GFAP promoter, can be cultured and transplanted, and there is evidence suggesting that $B D N F$ expression from these cells may selectively increase when neurotoxic stress is present [260, 261].

BDNF has incontrovertible therapeutic potential, primarily by activating several pro-survival kinase pathways (including Akt and MAPK), and has relevance in many neurodegenerative diseases [266]. However, despite the recent development of effective small molecule agonists for the BDNF receptor [267], the directed implantation of BDNF-secreting cells into a confined area may be safer in the long run. This is due to evidence that brain-wide hyperactivity of BDNF activity has been associated with a number of disorders including epilepsy, addiction, chronic pain, and depression [268].

Other neurotrophic factors have been delivered by transduced secreting cell implantation, including GDNF [269-271], Neurturin [272], and CNTF [273-275]. The CNTF studies are particularly interesting in that they were xenografts, but the cells survived in vivo by being encapsulated in a semipermeable membrane that renders them immunoisolated. However, this also prevents the cells from growing, which is safe in the context of undesirable hypertrophy but also necessitates a large amount of engrafted material for sufficient dosage. In the Phase I clinical trial [275], some electrophysiological improvements were seen in patients for whom the implanted capsules released the largest amount of CNTF, but cell survival was poor in more than half of the patients' capsules, stressing the need for improving both implanted cell survival and neurotrophic factor production.

\section{GENE THERAPY DELIVERY OF GROWTH FACTORS}

Implantation of transduced, engrafted cells is not the only way of achieving long-lasting growth factor supplementation. Gene therapy approaches (transduction of patient cells in vivo) are also beginning to be investigated for neurodegenerative diseases. Viral vectors for accomplishing this task are varied, but mainly are limited to vectors based on adenovirus, lentivirus, or adeno-associated virus (AAV), as all three 
can transduce postmitotic neurons. Adenovirus has fallen out of fashion due to high immunogenicity, but preclinical studies for all three have been effective. $\mathrm{AAV}$ and adenovirus have delivered a combination of Bdnf and noggin (Nog) in R6/2 transgenic mice and rat toxin models $[156,276]$. These studies were notable because the combination of neurotrophic factors actually induced neurogenesis. While this carries with it the risk for uncontrolled cell growth, it also offers the potential for neurorestoration in manifest patients whose striata have already suffered significant deterioration.

AAV-delivered Gdnf is also therapeutic in 3-NPtreated rats and N171-82Q transgenic mice [277, 278], but neurturin (Nrtn) has perhaps the most immediate potential due to the clinical trial safety data in the Parkinson's Disease field. AAV-delivered neurturin therapy, known as CERE-120, was tested in 6-OHDA treated rats (6-OHDA destroys dopaminergic nigrostriatal neurons, causing PD-like symptoms) and produced substantial therapeutic rescue with evidence of $\mathrm{Nrtn}$ expression out to at least 1 year post-transduction [279]. Clinical trials were initiated, with enough modest success to warrant protocol alterations and further clinical investigation [280-282]. Given the protective evidence of neurturin-secreting engrafted fibroblasts $[257,271]$ and demonstrated protection for AAV-Nrtn in toxin rat models of HD [283], the HD field will be anxiously watching CERE-120 progress, and if promising, its evaluation in HD could initiate before the end of the decade.

HD gene therapy treatment need not be limited to endogenous growth factors, and the immune privileged state of the CNS may in fact be the perfect place for expression of novel molecular therapeutics with minimal risk of inflammation due to the presence of foreign epitopes. Intracellular antibodies, single-chain non-secreted antibody fragments known as intrabodies, have significant potential. They can be directed to specific portions of the mHTT protein [284], and after delivery by AAV or lentivirus, have demonstrated significant neuroprotective potential [285, 286] likely by hastening mHTT turnover. In the context of mHTT's toxic oligomers but likely benign inclusions, demonstration that mHTT is actually degraded after intrabody treatment rather than simply showing reduction of inclusion size is the most promising part of this avenue. In that vein, using polyQ-binding peptides with Hsc70-recognition domains to directly drag mHTT to autophagosomes for chaperone-mediated autophagy is also promising, and reduces pathology in transgenic mice [287].

\section{PREVENTION RATHER THAN RESCUE: KNOCKDOWN APPROACHES FOR HD}

Growth factors, intrabodies, and peptides may have therapeutic potential by aiding the degradation of mHTT or reversing some of its downstream toxic pathways, but recent advances in RNAi therapeutics may soon make it possible to prevent mHTT's production in the first place. Making use of endogenous microRNA (miRNA) transcriptional regulation pathways, artificial short hairpin RNAs (shRNAs) or genetically modified miRNAs altered to target different sites have been investigated for safety and efficacy. Safety has a specific focus for such approaches in HD. The mutation in $m H T T$ is relatively subtle, so RNAibased therapeutics against the HTT transcript don't always differentiate between mutant and wild type alleles, depending on the target site. We know that wtHTT is essential, but heterozygous knockout mice have only subtle phenotypes [288]. Thus, it may be necessary to only transiently reduce $m H T T$ transcript levels and allow neurons the chance to "hit the reset button" on proteotoxic stress [289]. Limiting the effects on wtHTT and evaluating the safety of partial wtHTT knockdown have been just as much a focus of the HD RNAi therapeutic field as demonstrating therapeutic efficacy.

AAV-delivered shRNA constructs have been evaluated in transgenic murine HD models. The first such published study showed a strong ability to reduce mHTT RNA, protein, and inclusion levels, and to improve transcriptional dysregulation and behavioral dysfunction [290]. However, of the two constructs tested, both were equally effective at reducing $\mathrm{mHTT}$ RNA and proteins, but one of the two was highly toxic and actually exacerbated transcriptional profile alterations. This was likely the result of off target effects, a risk for any RNAi therapeutic as they often depend on the 6-base seed sequence to mediate most of their target specificity, and such 6-base sequences in shRNAs can be toxic if promiscuous [291]. Nevertheless, careful evaluation of off target risks can yield safe knockdown vectors, which have been evaluated and proven tolerable in primates [292, 293] and effective in murine HD models [294-296].

Harnessing the miRNA pathway is only one way nucleic acids can suppress mHTT levels, the other being chemically-modified oligonucleotides (oligos). Most promising is a chemically-modified oligo versus human HTT that specifically reduces human mHTT levels by $>50 \%$ in transgenic mouse models, and was somewhat effective in rhesus after intrathecal injection. Most remarkably, the protein reduction was maintained 
for up to 3 months in mice from a single 2-week-long intracranial infusion [297]. This surprising longevity is the result of the modified nucleic acid chemistry. Its cell penetrance was sufficient when the oligo was simply provided in a saline suspension. Additionally, altered oligonucleotide chemistry facilitates binding, cellular uptake, and nuclease resistance. This was achieved by using phosphorothioate rather than phosphodiester bonds between bases, as well as a base structure including 2'-O-methoxyethyl nucleosides on the outermost 5 bases rather than standard deoxynucleotides. Unlike small RNAs that use the RNAi pathway to reduce transcript levels, it requires no interaction with the RISC complex, instead relying on RNase $\mathrm{H}$ degrading the RNA portion of the RNA-DNA hybrid. That the modified DNA oligo is not degraded in the process allows it to be recycled, enhances longevity without diluting its knockdown capabilities, and avoids potential unintended modulation of the RNAi pathway by not serving as a substrate.

The above study was allele-specific only insofar as it was species specific. For true allele-specificity, one can potentially take advantage of common patient single nucleotide polymorphisms (SNPs). There is evidence that only 2 SNP-targeting oligos are needed to differentially target $m H T T$ in $2 / 3$ of patients [298]. Potent oligos have been targeted to SNP-bearing sequences in HTT [299], and humanized mouse models are being used to test them in a preclinical setting [300]. Nevertheless, it is worth noting that the presence of a SNP in a transcript does not necessarily mean that location would make a good target site for an oligo, as local secondary structure and RNA binding proteins in the region might modify an oligo's binding strength. Indeed, in the above studies, only four such SNP targets were found to provide both significant allele specificity and sufficient knockdown strength. The CAG repeat itself may also serve as an effective target for RNaseH mediated degradation of $m H T T$ transcripts, which would by definition be allele-specific [301]. However, there are many other mRNAs that include CAG repeats of significant length. This makes the evaluation of potential off target effects particularly important for this approach.

\section{FUTURE STRATEGIES FOR THERAPEUTIC ADVANCEMENT}

One of the primary reasons for the lack of an effective disease altering therapeutic in HD may be the diverse number of cellular pathways impacted by
mHTT. For drug trials, both preclinical and clinical, it is often difficult to specify the target and its effects, but with HD, careful targeting may not always be desirable. Given the diverse suite of symptoms, a drug with multiple effects may be ideal. For example, the compounds that are furthest along in the clinic (cysteamine, coenzyme Q10, and creatine) are all antioxidants, but coenzyme Q10 and creatine aid mitochondrial function [302, 303], while cysteamine has documented transcriptional rescue effects [304, 305]. An additional example of this would be the green tea extract compound EGCG, which not only can alter mHTT aggregation and toxicity in cell and fly models of HD, but also has antioxidant properties [306]. With these situations in mind, a viable strategy could be to identify those drugs with the greatest pleiotropic impact on the various phenotypes. This is not to suggest that the most worthy treatment modalities are only those with nonspecific targets; pleiotropic therapeutic rescue can also be achieved by highly targeted approaches such as the inhibition of specific histone deacetylases (HDACs). Because HDACs reduce access to chromatin (and hence transcription of genes) in a pleiotropic but predictable pattern, the objective is to identify drugs that only interfere with the function of the HDAC or HDACs most associated with targets of particular therapeutic value, while minimizing off target and harmful side effects [236, 237].

Furthermore, toxicity in HD affects multiple pathways, but there is nothing to say that multiple drugs cannot be co-administered. The progressive degeneration is clearly the result of the disruption of multiple pathways, so it is only logical that multi-drug regimens should be more thoroughly explored. This has already been attempted with coenzyme Q10 administered with remacemide (an NMDA receptor antagonist) [211, 307]. While this combination had no significant protective effect after 30 months of treatment in patients, it is remarkable in that it provided a substantial increase to survival in mice, greater than 30\% in R6/2 (an impressive feat given the strain's strong phenotype).

The different pathways to toxicity can be categorized any number of ways, but for simplicity's sake, let us divide them into four: trophic support, mitochondrial health (including $\mathrm{Ca}^{2+}$ homeostasis defects), transcriptional dysregulation, and proteostasis (both protein folding and degradation). All four of these categories contain both genetic modifier studies and pharmaceutical trials that significantly alter the motor phenotype and/or survival in mice. For trophic support, $B d n f$ overexpression is protective, as is the administration of agonists for its receptor [153, 267]. 
Mitochondrial health was impaired by Ppargcla (the gene for PGC1 $\alpha$ ) knockout and is boosted by creatine and coenzyme Q10 [75, 302, 303]. Transcriptional dysregulation is improved (albeit confusingly) by $\mathrm{Spl}$ knockout and by a number of HDAC inhibitors, such as SAHA [308, 309]. Finally, proteostasis is aided by $H s f 1$ overexpression and modestly improved in a different polyglutamine disease model (polyQ androgen receptor) by the Hsp90-inhibitor and geldanamycin analog 17-AAG [51, 220].

Considering that all of these individually aid HD mice, some of which with crossover effects in other pathways (cysteamine, a mitochondrial energetic booster and andioxidant, also improves BDNF protein levels in the brain) [304], it should be fairly straightforward to test combinations of them. The best candidates, with the fewest predicted contraindications, can be selected and initially tested pairwise and singly. Such experimental paradigms, particularly in animal models, could require a significant resource investment to robustly execute. Our lab is one of many that have worked to improve experimental throughput in mouse models [310]. Overall, clinical trials might produce more success if they are not dependent on a significant health improvement to neurons arising from only a single pathway's repair.

\section{SUMMARY}

This review has focused on well-established effects of mHTT on neuronal viability, the tools to measure the progress of disease in both manifest and premanifest patients, and the progress of current therapeutic efforts. Advancements in drug delivery, such as the use of nanoparticles for drug encapsulation or nonsurgical viral vector administration, and the strategies from the various CNS disease fields for penetrating the blood brain barrier after systemic drug delivery, are treasure troves of knowledge with relevance to $\mathrm{HD}$, but the exploration of which were omitted for space and scope reasons. As a field, there is much known about the pathogenic processes in HD and the possible treatments for them. The progress and enthusiasm at the bench for developing putative interventions for the bedside is encouraging, but patient populations for such trials are limited, and must be husbanded conservatively. Not every trial needs to be a sweeping success to have been worthwhile, but the failure rate of clinical trials in recent history tell us that that improvements are necessary. Firstly, the clinical trials likely need to be longer with better sensitivity and power to detect a reduction in symptoms, both behavioral and neuropathological. Secondly, preclinical models must improve in identifying when a therapeutic intervention has little to no potential in the clinic. The clinical and preclinical research communities have tremendous tools for both administering these potential treatments and, more importantly, assessing their efficacy with minimal invasiveness. The hope for a cure is therefore two-fold: that an effective treatment is found, and that its efficacy can be proven beyond doubt in patients. Both are necessary, and we believe that both are within reach.

The authors wish to dedicate this paper to the memory of Officer Sean Collier, for his caring service to the MIT community and for his sacrifice. This work was supported by funds from the Hereditary Disease Foundation, the National Institutes of Health Nanomedicine Development Centers Award (PN2) NOT-RM-05-010, the Koch Institute Support (core) Grant P30-CA14051 from the National Cancer Institute, and funds from The Leslie Gehry Brenner Prize for Innovation in Science. The authors declare no conflicts of interest.

\section{REFERENCES}

[1] Group THDCR. A novel gene containing a trinucleotide repeat that is expanded and unstable on Huntington's disease chromosomes. Cell. 1993;72:971-83.

[2] Nørremølle A, Riess O, Epplen JT, Fenger K, Hasholt L, Sørensen SA. Trinucleotide repeat elongation in the Huntingtin gene in Huntington disease patients from 71 Danish families. Hum Mol Genet. 1993;2:1475-6.

[3] Myers RH, MacDonald ME, Koroshetz WJ, Duyao MP, Ambrose CM, Taylor SA, Barnes G, Srinidhi J, Lin CS, Whaley WL, Lazzarini A, Schwarz M, Wolff G, Bird E, Vonsattel J-P, Gusella J. De novo expansion of a (CAG)n repeat in sporadic Huntington's disease. Nat Genet. 1993;5: 168-73.

[4] Bates G, Harper P, Jones L. Huntington's Disease, Oxford University Press, U S A, 2002.

[5] Slow EJ, van Raamsdonk J, Rogers D, Coleman SH, Graham RK, Deng Y, Oh R, Bissada N, Hossain SM, Yang Y-Z, Li X-J, Simpson EM, Gutekunst C-A, Leavitt BR, Hayden MR. Selective striatal neuronal loss in a YAC128 mouse model of Huntington disease. Hum Mol Genet. 2003;12(13):1555-67.

[6] Gray M, Shirasaki DI, Cepeda C, André VM, Wilburn B, Lu X-H, Tao J, Yamazaki I, Li S-H, Sun YE, Li X-J, Levine MS, Yang XW. Full-length human mutant huntingtin with a stable polyglutamine repeat can elicit progressive and selective neuropathogenesis in BACHD mice. J Neurosci. 2008;28(24):6182-95.

[7] Crook ZR, Housman D (2011) Huntington's disease: can mice lead the way to treatment? Neuron. 2011;69(3):423-35.

[8] Mangiarini L, Sathasivam K, Seller M, Cozens B, Harper A, Hetherington C, Lawton M, Trottier Y, Lehrach H, Davies SW, Bates GP. Exon 1 of the HD gene with an expanded CAG repeat is sufficient to cause a progressive neurological phenotype in transgenic mice. Cell. 1996;87:493-506. 
[9] DiFiglia M, Sapp E, Chase KO, Davies SW, Bates GP, Vonsattel JP, Aronin N. Aggregation of huntingtin in neuronal intranuclear inclusions and dystrophic neurites in brain. Science. 1997;277:1990-3.

[10] Yamada M, Sato T, Tsuji S, Takahashi H. CAG repeat disorder models and human neuropathology: Similarities and differences. Acta Neuropathol. 2008;115:71-86.

[11] Hackam AS, Singaraja R, Wellington CL, Metzler M, McCutcheon K, Zhang T, Kalchman M, Hayden MR. The influence of huntingtin protein size on nuclear localization and cellular toxicity. The Journal of Cell Biology. 1998;141:1097-105.

[12] Landles C, Sathasivam K, Weiss A, Woodman B, Moffitt H, Finkbeiner S, Sun B, Gafni J, Ellerby LM, Trottier Y, Richards WG, Osmand A, Paganetti P, Bates GP. Proteolysis of mutant huntingtin produces an exon 1 fragment that accumulates as an aggregated protein in neuronal nuclei in Huntington disease. Journal of Biological Chemistry. 2010;285:8808-23.

[13] Cooper JK, Schilling G, Peters MF, Herring WJ, Sharp AH, Kaminsky Z, Masone J, Khan FA, Delanoy M, Borchelt DR, Dawson VL, Dawson TM, Ross CA. Truncated N-terminal fragments of huntingtin with expanded glutamine repeats form nuclear and cytoplasmic aggregates in cell culture. Hum Mol Genet. 1998;7:783-90.

[14] Liu YF. Expression of polyglutamine-expanded Huntingtin activates the SEK1-JNK pathway and induces apoptosis in a hippocampal neuronal cell line. J Biol Chem. 1998;273:28873-7.

[15] Chen S, Berthelier V, Hamilton JB, O'Nuallain B, Wetzel R. Amyloid-like features of polyglutamine aggregates and their assembly kinetics. Biochemistry. 2002;41:7391-9.

[16] Thakur AK, Jayaraman M, Mishra R, Thakur M, Chellgren VM, Byeon I-JL, Anjum DH, Kodali R, Creamer TP, Conway JF, Gronenborn AM, Wetzel R. Polyglutamine disruption of the huntingtin exon $1 \mathrm{~N}$ terminus triggers a complex aggregation mechanism. Nat Struct Mol Biol. 2009;16:380-9.

[17] Wetzel R. Physical chemistry of polyglutamine: Intriguing tales of a monotonous sequence. J Mol Biol. 2012;421:46690.

[18] McGowan DP, van Roon-Mom W, Holloway H, Bates GP, Mangiarini L, Cooper GJ, Faull RL, Snell RG. Amyloid-like inclusions in Huntington's disease. NSC. 2000;100:677-80.

[19] Poirier MA, Li H, Macosko J, Cai S, Amzel M, Ross CA. Huntingtin spheroids and protofibrils as precursors in polyglutamine fibrilization. J Biol Chem. 2002;277:41032-7.

[20] Wood NI, Pallier PN, Wanderer J, Morton AJ. Systemic administration of Congo red does not improve motor or cognitive function in R6/2 mice. Neurobiology of Disease. 2007;25:342-53

[21] Sánchez I, Mahlke C, Yuan J. Pivotal role of oligomerization in expanded polyglutamine neurodegenerative disorders. Nature. 2003;421:373-9.

[22] Arrasate M, Mitra S, Schweitzer ES, Segal MR, Finkbeiner $S$. Inclusion body formation reduces levels of mutant huntingtin and the risk of neuronal death. Nature. 2004;431:805-10.

[23] Bowman AB, Yoo S-Y, Dantuma NP, Zoghbi HY. Neuronal dysfunction in a polyglutamine disease model occurs in the absence of ubiquitin-proteasome system impairment and inversely correlates with the degree of nuclear inclusion formation. Hum Mol Genet. 2005;14:679-91.

[24] Reiner A, del Mar N, Deng Y-P, Meade CA, Sun Z, Goldowitz D. R6/2 neurons with intranuclear inclusions sur- vive for prolonged periods in the brains of chimeric mice. J Comp Neurol. 2007;505:603-29.

[25] Yoshizawa T, Yoshida H, Shoji S. Differential susceptibility of cultured cell lines to aggregate formation and cell death produced by the truncated Machado-Joseph disease gene product with an expanded polyglutamine stretch. Brain Res Bull. 2001;56:349-52.

[26] Slow EJ, Graham RK, Osmand AP, Devon RS, Lu G, Deng Y, Pearson J, Vaid K, Bissada N, Wetzel R, Leavitt BR, Hayden MR. Absence of behavioral abnormalities and neurodegeneration in vivo despite widespread neuronal huntingtin inclusions. Proc Natl Acad Sci U S A. 2005;102:11402-7.

[27] Tebbenkamp ATN, Swing D, Tessarollo L, Borchelt DR. Premature death and neurologic abnormalities in transgenic mice expressing a mutant huntingtin exon-2 fragment. Hum Mol Genet. 2011;20:1633-42.

[28] Nucifora LG, Burke KA, Feng X, Arbez N, Zhu S, Miller J, Yang G, Ratovitski T, Delannoy M, Muchowski PJ, Finkbeiner S, Legleiter J, Ross CA, Poirier MA. Identification of novel potentially toxic oligomers formed in vitro from mammalian-derived expanded huntingtin exon1 protein. Journal of Biological Chemistry. 2012;287(19): 16017-28

[29] Manogaran AL, Hong JY, Hufana J, Tyedmers J, Lindquist S, Liebman SW. Prion formation and polyglutamine aggregation are controlled by two classes of genes. PLoS Genet. 2011;7:e1001386.

[30] Qin Z-H, Wang Y, Sapp E, Cuiffo B, Wanker E, Hayden MR, Kegel KB, Aronin N, Difiglia M. Huntingtin bodies sequester vesicle-associated proteins by a polyprolinedependent interaction. J Neurosci. 2004;24:269-81.

[31] Smith DL, Portier R, Woodman B, Hockly E, Mahal A, Klunk WE, Li X-J, Wanker E, Murray KD, Bates GP. Inhibition of polyglutamine aggregation in R6/2 HD brain slices-complex dose-response profiles. Neurobiology of Disease. 2001;8:1017-26.

[32] Stack EC, Kubilus JK, Smith K, Cormier K, del Signore SJ, Guelin E, Ryu H, Hersch SM, Ferrante RJ. Chronology of behavioral symptoms and neuropathological sequela in R6/2 Huntington's disease transgenic mice. J Comp Neurol. 2005;490:354-70.

[33] Suhr ST, Senut MC, Whitelegge JP, Faull KF, Cuizon DB, Gage FH. Identities of sequestered proteins in aggregates from cells with induced polyglutamine expression. The Journal of Cell Biology. 2001;153:283-94.

[34] Ravikumar B, Vacher C, Berger Z, Davies JE, Luo S, Oroz LG, Scaravilli F, Easton DF, Duden R, O'kane CJ, Rubinsztein DC. Inhibition of mTOR induces autophagy and reduces toxicity of polyglutamine expansions in fly and mouse models of Huntington disease. Nat Genet. 2004;36:585-95.

[35] Cha J-HJ. Transcriptional signatures in Huntington's disease. Prog Neurobiol. 2007;83:228-48.

[36] Yu Z-X, Li S-H, Nguyen HP, Li X-J. Huntingtin inclusions do not deplete polyglutamine-containing transcription factors in HD mice. Hum Mol Genet. 2002;11:905-14.

[37] Schaffar G, Breuer P, Boteva R, Behrends C, Tzvetkov N, Strippel N, Sakahira H, Siegers K, Hayer-Hartl M, Hartl FU. Cellular toxicity of polyglutamine expansion proteins: Mechanism of transcription factor deactivation. Mol Cell. 2004;15:95-105.

[38] Wyttenbach A, Carmichael J, Swartz J, Furlong RA, Narain Y, Rankin J, Rubinsztein DC. Effects of heat shock, heat shock protein 40 (HDJ-2), and proteasome inhibition 
on protein aggregation in cellular models of Huntington's disease. Proc Natl Acad Sci U S A. 2000;97:2898903.

[39] Jana NR, Tanaka M, Wang GH, Nukina N. Polyglutamine length-dependent interaction of Hsp40 and Hsp70 family chaperones with truncated $\mathrm{N}$-terminal huntingtin: Their role in suppression of aggregation and cellular toxicity. Hum Mol Genet. 2000;9:2009-18

[40] Wacker JL, Huang S-Y, Steele AD, Aron R, Lotz GP, Nguyen Q, Giorgini F, Roberson ED, Lindquist S, Masliah E, Muchowski PJ. Loss of Hsp70 exacerbates pathogenesis but not levels of fibrillar aggregates in a mouse model of Huntington's disease. J Neurosci. 2009;29:9104-14.

[41] Baldo B, Weiss A, Parker CN, Bibel M, Paganetti P, Kaupmann K. A screen for enhancers of clearance identifies huntingtin as an heat shock protein 90 (Hsp90) client protein. Journal of Biological Chemistry. 2012;287(2):1406-14

[42] Tagawa K, Marubuchi S, Qi M-L, Enokido Y, Tamura T, Inagaki R, Murata M, Kanazawa I, Wanker EE, Okazawa $H$. The induction levels of heat shock protein 70 differentiate the vulnerabilities to mutant huntingtin among neuronal subtypes. J Neurosci. 2007;27:868-80.

[43] Warrick JM, Chan HY, Gray-Board GL, Chai Y, Paulson HL, Bonini NM. Suppression of polyglutamine-mediated neurodegeneration in Drosophila by the molecular chaperone HSP70. Nat Genet. 1999;23:425-8.

[44] Chan HYE, Warrick JM, Andriola I, Merry D, Bonini NM. Genetic modulation of polyglutamine toxicity by protein conjugation pathways in Drosophila. Hum Mol Genet. 2002;11:2895-904.

[45] Al-Ramahi I, Lam YC, Chen H-K, de Gouyon B, Zhang M, Pérez AM, Branco J, de Haro M, Patterson C, Zoghbi HY, Botas J. CHIP protects from the neurotoxicity of expanded and wild-type ataxin-1 and promotes their ubiquitination and degradation. J Biol Chem. 2006;281:26714-24.

[46] Wang AM, Miyata Y, Klinedinst S, Peng H-M, Chua JP, Komiyama T, Li X, Morishima Y, Merry DE, Pratt WB, Osawa Y, Collins CA, Gestwicki JE, Lieberman AP. Activation of Hsp70 reduces neurotoxicity by promoting polyglutamine protein degradation. Nat Chem Biol. 2013;9(2):112-18

[47] Subramaniam S, Sixt KM, Barrow R, Snyder SH. Rhes, a striatal specific protein, mediates mutant-huntingtin cytotoxicity. Science. 2009;324:1327-30.

[48] Mitsui K, Nakayama H, Akagi T, Nekooki M, Ohtawa K, Takio K, Hashikawa T, Nukina N. Purification of polyglutamine aggregates and identification of elongation factor-1alpha and heat shock protein 84 as aggregateinteracting proteins. J Neurosci. 2002;22:9267-77.

[49] Hansson O, Nylandsted J, Castilho RF, Leist M, Jäättelä M, Brundin P. Overexpression of heat shock protein 70 in R6/2 Huntington's disease mice has only modest effects on disease progression. Brain Res. 2003;970:47-57.

[50] Hay DG, Sathasivam K, Tobaben S, Stahl B, Marber M, Mestril R, Mahal A, Smith DL, Woodman B, Bates GP. Progressive decrease in chaperone protein levels in a mouse model of Huntington's disease and induction of stress proteins as a therapeutic approach. Hum Mol Genet. 2004; $13: 1389-405$.

[51] Fujimoto M, Takaki E, Hayashi T, Kitaura Y, Tanaka Y, Inouye $\mathrm{S}$, Nakai A. Active HSF1 significantly suppresses polyglutamine aggregate formation in cellular and mouse models. J Biol Chem. 2005;280:34908-16.

[52] Hong DS, Banerji U, Tavana B, George GC, Aaron J, Kurzrock R. Targeting the molecular chaperone heat shock protein 90 (HSP90): Lessons learned and future directions. Cancer Treat Rev. 2013;39:375-87.

[53] Ji J, Sundquist K, Sundquist J. Cancer incidence in patients with polyglutamine diseases: A population-based study in Sweden. Lancet Oncol. 2012.

[54] Spiess C, Meyer AS, Reissmann S, Frydman J. Mechanism of the eukaryotic chaperonin: Protein folding in the chamber of secrets. Trends Cell Biol. 2004;14:598-604.

[55] Behrends C, Langer CA, Boteva R, Böttcher UM, Stemp MJ, Schaffar G, Rao BV, Giese A, Kretzschmar H, Siegers $\mathrm{K}$, Hartl FU. Chaperonin TRiC promotes the assembly of polyQ expansion proteins into nontoxic oligomers. Mol Cell. 2006;23:887-97.

[56] Tam S, Spiess C, Auyeung W, Joachimiak L, Chen B, Poirier MA, Frydman J. The chaperonin TRiC blocks a huntingtin sequence element that promotes the conformational switch to aggregation. Nat Struct Mol Biol. 2009;16:1279-85.

[57] Sontag EM, Joachimiak LA, Tan Z, Tomlinson A, Housman DE, Glabe CG, Potkin SG, Frydman J, Thompson LM. Exogenous delivery of chaperonin subunit fragment ApiCCT1 modulates mutant Huntingtin cellular phenotypes. Proc Natl Acad Sci U S A. 2013.

[58] Weeks RA, Piccini P, Harding AE, Brooks DJ. Striatal D1 and D2 dopamine receptor loss in asymptomatic mutation carriers of Huntington's disease. Ann Neurol. 1996;40:4954.

[59] Augood SJ, Faull RL, Emson PC. Dopamine D1 and D2 receptor gene expression in the striatum in Huntington's disease. Ann Neurol. 1997;42:215-21.

[60] Augood SJ, Faull RL, Love DR, Emson PC. Reduction in enkephalin and substance P messenger RNA in the striatum of early grade Huntington's disease: A detailed cellular in situ hybridization study. NSC. 1996;72:1023-36.

[61] Norris PJ, Waldvogel HJ, Faull RL, Love DR, Emson PC. Decreased neuronal nitric oxide synthase messenger RNA and somatostatin messenger RNA in the striatum of Huntington's disease. NSC. 1996;72:1037-47.

[62] Cornett J, Smith L, Friedman M, Shin J-Y, Li X-J, Li S-H. Context-dependent dysregulation of transcription by mutant huntingtin. J Biol Chem. 2006;281:36198-204.

[63] Zuccato C, Tartari M, Crotti A, Goffredo D, Valenza M, Conti L, Cataudella T, Leavitt BR, Hayden MR, Timmusk T, Rigamonti D, Cattaneo E. Huntingtin interacts with REST/NRSF to modulate the transcription of NRSEcontrolled neuronal genes. Nat Genet. 2003;35:76-83.

[64] Shimojo M. Huntingtin regulates RE1-silencing transcription factor/neuron-restrictive silencer factor (REST/NRSF) nuclear trafficking indirectly through a complex with REST/NRSF-interacting LIM domain protein (RILP) and dynactin p150 Glued. J Biol Chem. 2008;283:34880-6.

[65] Hodges A, Strand AD, Aragaki AK, Kuhn A, Sengstag T, Hughes G, Elliston LA, Hartog C, Goldstein DR, Thu D, Hollingsworth ZR, Collin F, Synek B, Holmans PA, Young AB, Wexler NS, Delorenzi M, Kooperberg C, Augood SJ, Faull RLM, Olson JM, Jones L, Luthi-Carter R. Regional and cellular gene expression changes in human Huntington's disease brain. Hum Mol Genet. 2006;15:965-77.

[66] Borovecki F, Lovrecic L, Zhou J, Jeong H, Then F, Rosas HD, Hersch SM, Hogarth P, Bouzou B, Jensen RV, Krainc D. Genome-wide expression profiling of human blood reveals biomarkers for Huntington's disease. Proc Natl Acad Sci U S A. 2005;102:11023-8.

[67] Strand AD, Aragaki AK, Shaw D, Bird T, Holton J, Turner C, Tapscott SJ, Tabrizi SJ, Schapira AH, Kooperberg C, Olson JM. Gene expression in Huntington's disease 
skeletal muscle: A potential biomarker. Hum Mol Genet. 2005; 14:1863-76.

[68] Luthi-Carter R, Strand A, Peters NL, Solano SM, Hollingsworth ZR, Menon AS, Frey AS, Spektor BS, Penney EB, Schilling G, Ross CA, Borchelt DR, Tapscott SJ, Young AB, Cha JH, Olson JM. Decreased expression of striatal signaling genes in a mouse model of Huntington's disease. Hum Mol Genet. 2000;9:1259-71.

[69] Hodges A, Hughes G, Brooks S, Elliston L, Holmans P, Dunnett SB, Jones L. Brain gene expression correlates with changes in behavior in the R6/1 mouse model of Huntington's disease. Genes Brain Behav. 2008;7:288-99.

[70] Strand AD, Baquet ZC, Aragaki AK, Holmans P, Yang L, Cleren C, Beal MF, Jones L, Kooperberg C, Olson JM, Jones KR. Expression profiling of Huntington's disease models suggests that brain-derived neurotrophic factor depletion plays a major role in striatal degeneration. J Neurosci. 2007;27:11758-68

[71] Johnson R, Buckley NJ. Gene dysregulation in Huntington's disease: REST, microRNAs and beyond. Neuromol Med. 2009;11:183-99.

[72] Altar CA, Cai N, Bliven T, Juhasz M, Conner JM, Acheson AL, Lindsay RM, Wiegand SJ. Anterograde transport of brain-derived neurotrophic factor and its role in the brain. Nature. 1997;389:856-60.

[73] Zuccato C, Cattaneo E. Role of brain-derived neurotrophic factor in Huntington's disease. Prog Neurobiol. 2007;81:294-330.

[74] Zuccato C, Belyaev N, Conforti P, Ooi L, Tartari M, Papadimou E, MacDonald M, Fossale E, Zeitlin S, Buckley N, Cattaneo E. Widespread disruption of repressor element-1 silencing transcription factor/neuron-restrictive silencer factor occupancy at its target genes in Huntington's disease. J Neurosci. 2007;27:6972-83.

[75] Cui L, Jeong H, Borovecki F, Parkhurst CN, Tanese N, Krainc D. Transcriptional repression of PGC-1alpha by mutant huntingtin leads to mitochondrial dysfunction and neurodegeneration. Cell. 2006;127:59-69.

[76] Chaturvedi RK, Calingasan NY, Yang L, Hennessey T, Johri A, Beal MF. Impairment of PGC-1alpha expression, neuropathology and hepatic steatosis in a transgenic mouse model of Huntington's disease following chronic energy deprivation. Hum Mol Genet. 2010;19:3190-205.

[77] Lin J, Wu P-H, Tarr PT, Lindenberg KS, St-Pierre J, Zhang C-Y, Mootha VK, Jäger S, Vianna CR, Reznick RM, Cui L, Manieri M, Donovan MX, Wu Z, Cooper MP, Fan MC, Rohas LM, Zavacki AM, Cinti S, Shulman GI, Lowell BB, Krainc D, Spiegelman BM. Defects in adaptive energy metabolism with CNS-linked hyperactivity in PGC-1alpha null mice. Cell 2004;119:121-35.

[78] Mitra S, Tsvetkov AS, Finkbeiner S. Protein turnover and inclusion body formation. Autophagy. 2009;5: 1037-8.

[79] Waelter S, Boeddrich A, Lurz R, Scherzinger E, Lueder G, Lehrach H, Wanker EE. Accumulation of mutant huntingtin fragments in aggresome-like inclusion bodies as a result of insufficient protein degradation. Mol Biol Cell. 2001;12:1393-407.

[80] Venkatraman P, Wetzel R, Tanaka M, Nukina N, Goldberg AL. Eukaryotic proteasomes cannot digest polyglutamine sequences and release them during degradation of polyglutamine-containing proteins. Mol Cell. 2004;14:95104.

[81] Qin Z-H, Wang Y, Kegel KB, Kazantsev A, Apostol BL, Thompson LM, Yoder J, Aronin N, Difiglia M. Autophagy regulates the processing of amino terminal huntingtin fragments. Hum Mol Genet. 2003;12:3231-44.

[82] Roscic A, Baldo B, Crochemore C, Marcellin D, Paganetti P. Induction of autophagy with catalytic mTOR inhibitors reduces huntingtin aggregates in a neuronal cell model. J Neurochem. 2011;119:398-407.

[83] Duan W, Guo Z, Jiang H, Ware M, Li X-J, Mattson MP. Dietary restriction normalizes glucose metabolism and BDNF levels, slows disease progression, and increases survival in huntingtin mutant mice. Proc Natl Acad Sci U S A. 2003;100:2911-6.

[84] Atwal RS, Xia J, Pinchev D, Taylor J, Epand RM, Truant $R$. Huntingtin has a membrane association signal that can modulate huntingtin aggregation, nuclear entry and toxicity. Hum Mol Genet. 2007;16:2600-15.

[85] Kegel KB, Kim M, Sapp E, McIntyre C, Castaño JG, Aronin N, DiFiglia M. Huntingtin expression stimulates endosomal-lysosomal activity, endosome tubulation, and autophagy. J Neurosci. 2000;20:7268-78.

[86] Jeong H, Then F, Melia TJ, Mazzulli JR, Cui L, Savas JN, Voisine C, Paganetti P, Tanese N, Hart AC, Yamamoto A, Krainc D. Acetylation targets mutant huntingtin to autophagosomes for degradation. Cell. 2009;137:60-72.

[87] Koga H, Martinez-Vicente M, Arias E, Kaushik S, Sulzer D, Cuervo AM. Constitutive upregulation of chaperonemediated autophagy in Huntington's disease. J Neurosci. 2011;31:18492-505.

[88] Metzger S, Saukko M, Van Che H, Tong L, Puder Y, Riess $\mathrm{O}$, Nguyen HP. Age at onset in Huntington's disease is modified by the autophagy pathway: Implication of the V471A polymorphism in Atg7. Hum Genet. 2010;128:453-9.

[89] Beal MF, Brouillet E, Jenkins BG, Ferrante RJ, Kowall NW, Miller JM, Storey E, Srivastava R, Rosen BR, Hyman BT. Neurochemical and histologic characterization of striatal excitotoxic lesions produced by the mitochondrial toxin 3-nitropropionic acid. J Neurosci. 1993;13:4181-92.

[90] Saulle E, Gubellini P, Picconi B, Centonze D, Tropepi D, Pisani A, Morari M, Marti M, Rossi L, Papa M, Bernardi G, Calabresi P. Neuronal vulnerability following inhibition of mitochondrial complex II: A possible ionic mechanism for Huntington's disease. Mol Cell Neurosci. 2004;25: 9-20.

[91] Acevedo-Torres K, Berríos L, Rosario N, Dufault V, Skatchkov S, Eaton MJ, Torres-Ramos CA, Ayala-Torres S. Mitochondrial DNA damage is a hallmark of chemically induced and the R6/2 transgenic model of Huntington's disease. DNA Repair (Amst.). 2009;8:126-36.

[92] Fontaine MA, Geddes JW, Banks A, Butterfield DA. Effect of exogenous and endogenous antioxidants on 3nitropionic acid-induced in vivo oxidative stress and striatal lesions: insights into Huntington's disease. J Neurochem. 2000;75:1709-15.

[93] Solesio ME, Saez-Atienzar S, Jordan J, Galindo MF. 3-Nitropropionic acid induces autophagy by forming mitochondrial permeability transition pores rather than activating the mitochondrial fission pathway. Br J Pharmacol. 2013;168(1):63-75.

[94] Rosenstock TR, Carvalho ACP, Jurkiewicz A, Frussa-Filho R, Smaili SS. Mitochondrial calcium, oxidative stress and apoptosis in a neurodegenerative disease model induced by 3-nitropropionic acid. J Neurochem. 2004;88:1220-8.

[95] Pickrell AM, Fukui H, Wang X, Pinto M, Moraes CT. The striatum is highly susceptible to mitochondrial oxidative phosphorylation dysfunctions. J Neurosci. 2011;31:9895904. 
[96] Gu M, Gash MT, Mann VM, Javoy-Agid F, Cooper JM, Schapira AH. Mitochondrial defect in Huntington's disease caudate nucleus. Ann Neurol. 1996;39:385-9.

[97] Guidetti P, Charles V, Chen EY, Reddy PH, Kordower JH, Whetsell WO, Schwarcz R, Tagle DA. Early degenerative changes in transgenic mice expressing mutant huntingtin involve dendritic abnormalities but no impairment of mitochondrial energy production. Experimental Neurology. 2001;169:340-50.

[98] Browne SE, Bowling AC, MacGarvey U, Baik MJ, Berger SC, Muqit MM, Bird ED, Beal MF. Oxidative damage and metabolic dysfunction in Huntington's disease: Selective vulnerability of the basal ganglia. Ann Neurol. 1997;41:64653.

[99] Seong IS, Ivanova E, Lee J-M, Choo YS, Fossale E, Anderson M, Gusella JF, Laramie JM, Myers RH, Lesort M, Macdonald ME. HD CAG repeat implicates a dominant property of huntingtin in mitochondrial energy metabolism. Hum Mol Genet. 2005;14:2871-80.

[100] Weydt P, Pineda VV, Torrence AE, Libby RT, Satterfield TF, Lazarowski ER, Gilbert ML, Morton GJ, Bammler TK, Strand AD, Cui L, Beyer RP, Easley CN, Smith AC, Krainc D, Luquet S, Sweet IR, Schwartz MW, La Spada AR. Thermoregulatory and metabolic defects in Huntington"s disease transgenic mice implicate PGC-1alpha in Huntington"s disease neurodegeneration. Cell Metab. 2006;4:349-62.

[101] Bogdanov MB, Andreassen OA, Dedeoglu A, Ferrante RJ, Beal MF. Increased oxidative damage to DNA in a transgenic mouse model of Huntington's disease. J Neurochem. 2001;79:1246-9.

[102] Choo YS, Mao Z, Johnson GVW, Lesort M. Increased glutathione levels in cortical and striatal mitochondria of the R6/2 Huntington's disease mouse model. Neurosci Lett. 2005;386:63-8.

[103] Bogdanov MB, Ferrante RJ, Kuemmerle S, Klivenyi P, Beal MF. Increased vulnerability to 3-nitropropionic acid in an animal model of Huntington's disease. J Neurochem. 1998;71:2642-4.

[104] Gines S, Seong IS, Fossale E, Ivanova E, Trettel F, Gusella JF, Wheeler VC, Persichetti F, Macdonald ME. Specific progressive cAMP reduction implicates energy deficit in presymptomatic Huntington's disease knock-in mice. Hum Mol Genet. 2003;12:497-508.

[105] Trushina E, Dyer RB, Badger JD, Ure D, Eide L, Tran DD, Vrieze BT, Legendre-Guillemin V, McPherson PS, Mandavilli BS, van Houten B, Zeitlin S, McNiven M, Aebersold R, Hayden M, Parisi JE, Seeberg E, Dragatsis I, Doyle K, Bender A, Chacko C, McMurray CT. Mutant huntingtin impairs axonal trafficking in mammalian neurons in vivo and in vitro. Mol Cell Biol. 2004;24:8195-209.

[106] Orr AL, Li S, Wang C-E, Li H, Wang J, Rong J, Xu X, Mastroberardino PG, Greenamyre JT, Li X-J. Nterminal mutant huntingtin associates with mitochondria and impairs mitochondrial trafficking. J Neurosci. 2008;28: 2783-92.

[107] Squitieri F, Cannella M, Sgarbi G, Maglione V, Falleni A, Lenzi P, Baracca A, Cislaghi G, Saft C, Ragona G, Russo MA, Thompson LM, Solaini G, Fornai F. Severe ultrastructural mitochondrial changes in lymphoblasts homozygous for Huntington disease mutation. Mech Ageing Dev. 2006;127:217-20.

[108] Squitieri F, Falleni A, Cannella M, Orobello S, Fulceri F, Lenzi P, Fornai F. Abnormal morphology of peripheral cell tissues from patients with Huntington disease. J Neural Transm. 2010;117:77-83.
[109] Smirnova E, Griparic L, Shurland DL, van der Bliek AM. Dynamin-related protein Drp1 is required for mitochondrial division in mammalian cells. Mol Biol Cell. 2001;12:224556.

[110] Kim J, Moody JP, Edgerly CK, Bordiuk OL, Cormier K, Smith K, Beal MF, Ferrante RJ. Mitochondrial loss, dysfunction and altered dynamics in Huntington's disease. Hum Mol Genet. 2010;19:3919-35.

[111] Shirendeb U, Reddy AP, Manczak M, Calkins MJ, Mao P, Tagle DA, Reddy PH. Abnormal mitochondrial dynamics, mitochondrial loss and mutant huntingtin oligomers in Huntington's disease: Implications for selective neuronal damage. Hum Mol Genet. 2011;20:1438-55.

[112] Shirendeb UP, Calkins MJ, Manczak M, Anekonda V, Dufour B, McBride JL, Mao P, Reddy PH. Mutant huntingtin"s interaction with mitochondrial protein Drp1 impairs mitochondrial biogenesis and causes defective axonal transport and synaptic degeneration in Huntington"s disease. Hum Mol Genet. 2012;21:406-20.

[113] Song W, Chen J, Petrilli A, Liot G, Klinglmayr E, Zhou Y, Poquiz P, Tjong J, Pouladi MA, Hayden MR, Masliah E, Ellisman M, Rouiller I, Schwarzenbacher R, Bossy B, Perkins G, Bossy-Wetzel E. Mutant huntingtin binds the mitochondrial fission GTPase dynamin-related protein-1 and increases its enzymatic activity. Nat Med. 2011;17:37782.

[114] Costa V, Giacomello M, Hudec R, Lopreiato R, Ermak G, Lim D, Malorni W, Davies KJA, Carafoli E, Scorrano L. Mitochondrial fission and cristae disruption increase the response of cell models of Huntington's disease to apoptotic stimuli. EMBO Mol Med. 2010;2:490-503.

[115] Wang H, Lim PJ, Karbowski M, Monteiro MJ. Effects of overexpression of huntingtin proteins on mitochondrial integrity. Hum Mol Genet. 2009;18:737-52.

[116] Mattson MP. Calcium and neurodegeneration. Aging Cell. 2007;6:337-50

[117] Gizatullina ZZ, Lindenberg KS, Harjes P, Chen Y, Kosinski CM, Landwehrmeyer BG, Ludolph AC, Striggow F, Zierz S, Gellerich FN. Low stability of Huntington muscle mitochondria against $\mathrm{Ca} 2+$ in R6/2 mice. Ann Neurol. 2006;59:407-11.

[118] Fernandes HB, Baimbridge KG, Church J, Hayden MR, Raymond LA. Mitochondrial sensitivity and altered calcium handling underlie enhanced NMDA-induced apoptosis in YAC128 model of Huntington's disease. J Neurosci. 2007;27:13614-23.

[119] Panov A, Obertone T, Bennett-Desmelik J, Greenamyre JT. $\mathrm{Ca}(2+)$-dependent permeability transition and complex I activity in lymphoblast mitochondria from normal individuals and patients with Huntington"s or Alzheimer"s disease. Ann N Y Acad Sci. 1999;893:365-8.

[120] Olney JW, Rhee V, Ho OL. Kainic acid: A powerful neurotoxic analogue of glutamate. Brain Res. 1974;77:507-12.

[121] Coyle JT, Schwarcz R. Lesion of striatal neurones with kainic acid provides a model for Huntington's chorea. Nature. 1976;263:244-6.

[122] Beal MF, Kowall NW, Ellison DW, Mazurek MF, Swartz KJ, Martin JB. Replication of the neurochemical characteristics of Huntington's disease by quinolinic acid. Nature. 1986;321:168-71.

[123] Beal MF, Ferrante RJ, Swartz KJ, Kowall NW. Chronic quinolinic acid lesions in rats closely resemble Huntington's disease. J Neurosci. 1991;11:1649-59.

[124] Ferrante RJ, Kowall NW, Cipolloni PB, Storey E, Beal MF. Excitotoxin lesions in primates as a model for Huntington's 
disease: Histopathologic and neurochemical characterization. Experimental Neurology. 1993;119:46-71.

[125] Campesan S, Green EW, Breda C, Sathyasaikumar KV, Muchowski PJ, Schwarcz R, Kyriacou CP, Giorgini F. The kynurenine pathway modulates neurodegeneration in a Drosophila model of Huntington's disease. Curr Biol. 2011;21:961-6.

[126] Zwilling D, Huang S-Y, Sathyasaikumar KV, Notarangelo FM, Guidetti P, Wu H-Q, Lee J, Truong J, Andrews-Zwilling Y, Hsieh EW, Louie JY, Wu T, Scearce-Levie K, Patrick C, Adame A, Giorgini F, Moussaoui S, Laue G, Rassoulpour A, Flik G, Huang Y, Muchowski JM, Masliah E, Schwarcz R, Muchowski PJ. Kynurenine 3-monooxygenase inhibition in blood ameliorates neurodegeneration. Cell. 2011;145:86374.

[127] Wahl A-S, Buchthal B, Rode F, Bomholt SF, Freitag HE, Hardingham GE, Rønn LCB, Bading H. Hypoxic/ischemic conditions induce expression of the putative pro-death gene Clca1 via activation of extrasynaptic N-methyl-D-aspartate receptors. NSC. 2009;158:344-52.

[128] Li L, Murphy TH, Hayden MR, Raymond LA. Enhanced striatal NR2B-containing N-methyl-D-aspartate receptormediated synaptic currents in a mouse model of Huntington disease. J Neurophysiol. 2004;92:2738-46.

[129] Li L, Fan M, Icton CD, Chen N, Leavitt BR, Hayden MR, Murphy TH, Raymond LA. Role of NR2B-type NMDA receptors in selective neurodegeneration in Huntington disease. Neurobiol Aging. 2003;24:1113-21.

[130] Tang T-S, Slow E, Lupu V, Stavrovskaya IG, Sugimori M, Llinás R, Kristal BS, Hayden MR, Bezprozvanny I. Disturbed $\mathrm{Ca} 2+$ signaling and apoptosis of medium spiny neurons in Huntington's disease. Proc Natl Acad Sci U S A. 2005;102:2602-7.

[131] Heng MY, Detloff PJ, Wang PL, Tsien JZ, Albin RL. In Vivo Evidence for NMDA Receptor-Mediated Excitotoxicity in a Murine Genetic Model of Huntington Disease. J Neurosci. 2009;29:3200-5

[132] Gladding CM, Sepers MD, Xu J, Zhang LYJ, Milnerwood AJ, Lombroso PJ, Raymond LA. Calpain and STriatalEnriched protein tyrosine phosphatase (STEP) activation contribute to extrasynaptic NMDA receptor localization in a Huntington's disease mouse model. Hum Mol Genet. 2012;21:3739-52.

[133] Kaufman AM, Milnerwood AJ, Sepers MD, Coquinco A, She K, Wang L, Lee H, Craig AM, Cynader M, Raymond LA. Opposing Roles of Synaptic and Extrasynaptic NMDA Receptor Signaling in Cocultured Striatal and Cortical Neurons. J Neurosci. 2012:32:3992-4003.

[134] Graham RK, Pouladi MA, Joshi P, Lu G, Deng Y, Wu N-P, Figueroa BE, Metzler M, Andre VM, Slow EJ, Raymond L, Friedlander R, Levine MS, Leavitt BR, Hayden MR. Differential Susceptibility to Excitotoxic Stress in YAC128 Mouse Models of Huntington Disease between Initiation and Progression of Disease. J Neurosci. 2009;29: 2193-204.

[135] Cowan CM, Fan MMY, Fan J, Shehadeh J, Zhang LYJ, Graham RK, Hayden MR, Raymond LA. PolyglutamineModulated Striatal Calpain Activity in YAC Transgenic Huntington Disease Mouse Model: Impact on NMDA Receptor Function and Toxicity. J Neurosci. 2008;28:1272535.

[136] Dedeoglu A, Ferrante RJ, Andreassen OA, Dillmann WH, Beal MF. Mice overexpressing 70-kDa heat shock protein show increased resistance to malonate and 3-nitropropionic acid. Experimental Neurology. 2002;176:262-5.
[137] Crook ZR, Housman DE. Huntington's Disease: Can Mice Lead the Way to Treatment? Neuron. 2011;69:423-35.

[138] Sorolla MA, Rodríguez-Colman MJ, Tamarit J, Ortega Z, Lucas JJ, Ferrer I, Ros J, Cabiscol E. Protein oxidation in Huntington disease affects energy production and vitamin B6 metabolism. Free Radic Biol Med. 2010;49:612-21.

[139] Chatterjee M, Andrulis M, Stühmer T, Müller E, Hofmann C, Steinbrunn T, Heimberger T, Schraud H, Kressmann $\mathrm{S}$, Einsele H, Bargou RC. The PI3K/Akt signalling pathway regulates the expression of Hsp70, which critically contributes to Hsp90-chaperone function and tumor cell survival in multiple myeloma. Haematologica. 2013;98(7): 1132-41.

[140] Gines S, Ivanova E, Seong IS, Saura CA, Macdonald ME. Enhanced Akt signaling is an early pro-survival response that reflects $\mathrm{N}$-methyl-D-aspartate receptor activation in Huntington's disease knock-in striatal cells. J Biol Chem. 2003:278:50514-22.

[141] Leavitt BR, van Raamsdonk JM, Shehadeh J, Fernandes H, Murphy Z, Graham RK, Wellington CL, Raymond LA, Hayden MR. Wild-type huntingtin protects neurons from excitotoxicity. J Neurochem. 2006;96:1121-9.

[142] Graham RK, Deng Y, Slow EJ, Haigh B, Bissada N, Lu G, Pearson J, Shehadeh J, Bertram L, Murphy Z, Warby SC, Doty CN, Roy S, Wellington CL, Leavitt BR, Raymond LA, Nicholson DW, Hayden MR. Cleavage at the caspase-6 site is required for neuronal dysfunction and degeneration due to mutant huntingtin. Cell. 2006;125:1179-91.

[143] Shirasaki DI, Greiner ER, Al-Ramahi I, Gray M, Boontheung P, Geschwind DH, Botas J, Coppola G, Horvath S, Loo JA, Yang XW. Network organization of the huntingtin proteomic interactome in mammalian brain. Neuron. 2012;75:41-57.

[144] Zhang H, Li Q, Graham RK, Slow E, Hayden MR, Bezprozvanny I. Full length mutant huntingtin is required for altered $\mathrm{Ca} 2+$ signaling and apoptosis of striatal neurons in the YAC mouse model of Huntington's disease. Neurobiology of Disease. 2008;31:80-8.

[145] Stack EC, Dedeoglu A, Smith KM, Cormier K, Kubilus JK, Bogdanov M, Matson WR, Yang L, Jenkins BG, LuthiCarter R, Kowall NW, Hersch SM, Beal MF, Ferrante RJ. Neuroprotective effects of synaptic modulation in Huntington's disease R6/2 mice. J Neurosci. 2007;27:12908-15.

[146] Metzler M, Gan L, Wong TP, Liu L, Helm J, Liu L, Georgiou J, Wang Y, Bissada N, Cheng K, Roder JC, Wang YT, Hayden MR. NMDA receptor function and NMDA receptor-dependent phosphorylation of huntingtin is altered by the endocytic protein HIP1. J Neurosci. 2007;27: 2298-308

[147] Metzler M, Gan L, Mazarei G, Graham RK, Liu L, Bissada N, Lu G, Leavitt BR, Hayden MR. Phosphorylation of huntingtin at Ser421 in YAC128 neurons is associated with protection of YAC128 neurons from NMDA-mediated excitotoxicity and is modulated by PP1 and PP2A. J Neurosci. 2010;30:14318-29.

[148] Xifró X, García-Martínez JM, del Toro D, Alberch J, PérezNavarro E. Calcineurin is involved in the early activation of NMDA-mediated cell death in mutant huntingtin knock-in striatal cells. J Neurochem. 2008;105:1596-612.

[149] Zala D, Colin E, Rangone H, Liot G, Humbert S, Saudou F. Phosphorylation of mutant huntingtin at S421 restores anterograde and retrograde transport in neurons. Hum Mol Genet. 2008;17:3837-46.

[150] Warby SC, Doty CN, Graham RK, Shively J, Singaraja $R R$, Hayden MR. Phosphorylation of huntingtin reduces the 
accumulation of its nuclear fragments. Mol Cell Neurosci. 2009;40:121-7.

[151] Colin E, Zala D, Liot G, Rangone H, Borrell-Pagès M, Li $\mathrm{X}-\mathrm{J}$, Saudou F, Humbert S. Huntingtin phosphorylation acts as a molecular switch for anterograde/retrograde transport in neurons. EMBO J. 2008;27:2124-34.

[152] Pardo R, Colin E, Régulier E, Aebischer P, Déglon N, Humbert S, Saudou F. Inhibition of calcineurin by FK506 protects against polyglutamine-huntingtin toxicity through an increase of huntingtin phosphorylation at S421. J Neurosci. 2006;26:1635-45.

[153] Xie Y, Hayden MR, Xu B. BDNF overexpression in the forebrain rescues Huntington's disease phenotypes in YAC128 mice. J Neurosci. 2010;30:14708-18.

[154] Pineda JR, Pardo R, Zala D, Yu H, Humbert S, Saudou F. Genetic and pharmacological inhibition of calcineurin corrects the BDNF transport defect in Huntington's disease. Mol Brai. 2009;2:33.

[155] Canals JM, Pineda JR, Torres-Peraza JF, Bosch M, MartínIbañez R, Muñoz MT, Mengod G, Ernfors P, Alberch J. Brain-derived neurotrophic factor regulates the onset and severity of motor dysfunction associated with enkephalinergic neuronal degeneration in Huntington's disease. J Neurosci. 2004;24:7727-39.

[156] Cho S-R, Benraiss A, Chmielnicki E, Samdani A, Economides A, Goldman SA. Induction of neostriatal neurogenesis slows disease progression in a transgenic murine model of Huntington disease. J Clin Invest. 2007;117:2889902.

[157] Gharami K, Xie Y, An JJ, Tonegawa S, Xu B. Brainderived neurotrophic factor over-expression in the forebrain ameliorates Huntington's disease phenotypes in mice. J Neurochem. 2008;105:369-79.

[158] Group THS. Unified Huntington's Disease Rating Scale: Reliability and consistency. Huntington Study Group. Mov Disord. 1996;11:136-42.

[159] Bäckman L, Robins-Wahlin TB, Lundin A, Ginovart N, Farde L. Cognitive deficits in Huntington's disease are predicted by dopaminergic PET markers and brain volumes. Brain. 1997; 120(Pt 12):2207-17

[160] Penney JB, Vonsattel JP, MacDonald ME, Gusella JF, Myers RH. CAG repeat number governs the development rate of pathology in Huntington's disease. Ann Neurol. 1997;41:689-92.

[161] Antonini A, Leenders KL, Eidelberg D. [11C]raclopridePET studies of the Huntington's disease rate of progression: Relevance of the trinucleotide repeat length. Ann Neurol. 1998;43:253-5.

[162] Rosas HD, Koroshetz WJ, Chen YI, Skeuse C, Vangel M, Cudkowicz ME, Caplan K, Marek K, Seidman LJ, Makris N, Jenkins BG, Goldstein JM. Evidence for more widespread cerebral pathology in early HD: An MRI-based morphometric analysis. Neurology. 2003;60:1615-20.

[163] Fennema-Notestine C, Archibald SL, Jacobson MW, CoreyBloom J, Paulsen JS, Peavy GM, Gamst AC, Hamilton JM, Salmon DP, Jernigan TL. In vivo evidence of cerebellar atrophy and cerebral white matter loss in Huntington disease. Neurology. 2004;63:989-95.

[164] Vonsattel JP, DiFiglia M. Huntington disease. J Neuropathol Exp Neurol. 1998;57:369-84.

[165] Petersén A, Björkqvist M. Hypothalamic-endocrine aspects in Huntington's disease. Eur J Neurosci. 2006;24: 961-7.

[166] Aziz NA, Pij1 H, Frölich M, van der Graaf AWM, Roelfsema F, Roos RAC. Increased hypothalamic-pituitary-adrenal axis activity in Huntington's disease. J Clin Endocrinol Metab. 2009;94:1223-8.

[167] Waldvogel HJ, Kim EH, Thu DC, Tippett LJ, Faull RL. New Perspectives on the Neuropathology in Huntington's Disease in the Human Brain and its Relation to Symptom Variation. J Huntingtons Dis. 2012;1:143-53.

[168] Rattray I, Smith E, Gale R, Matsumoto K, Bates GP, Modo M. Correlations of Behavioral Deficits with Brain Pathology Assessed through Longitudinal MRI and Histopathology in the R6/2 Mouse Model of HD. PLoS ONE. 2013;8: e60012.

[169] Aggarwal M, Duan W, Hou Z, Rakesh N, Peng Q, Ross CA, Miller MI, Mori S, Zhang J. Spatiotemporal mapping of brain atrophy in mouse models of Huntington's disease using longitudinal in vivo magnetic resonance imaging. Neuroimage. 2012;60:2086-95.

[170] Thu DCV, Oorschot DE, Tippett LJ, Nana AL, Hogg VM, Synek BJ, Luthi-Carter R, Waldvogel HJ, Faull RLM. Cell loss in the motor and cingulate cortex correlates with symptomatology in Huntington's disease. Brain. 2010;133:1094-110.

[171] Ciarmiello A, Cannella M, Lastoria S, Simonelli M, Frati L, Rubinsztein DC, Squitieri F. Brain white-matter volume loss and glucose hypometabolism precede the clinical symptoms of Huntington's disease. J Nucl Med. 2006;47:215-22.

[172] Kim J, Amante DJ, Moody JP, Edgerly CK, Bordiuk OL, Smith K, Matson SA, Matson WR, Scherzer CR, Rosas HD, Hersch SM, Ferrante RJ. Reduced creatine kinase as a central and peripheral biomarker in Huntington's disease. Biochim Biophys Acta. 2010;1802:673-81.

[173] Long JD, Matson WR, Juhl AR, Leavitt BR, Paulsen JS, the PREDICT-HD Investigators and Coordinators of the Huntington Study Group. $8 \mathrm{OHdG}$ as a marker for Huntington disease progression. Neurobiology of Disease. 2012;46(3):625-34.

[174] Chen C-M, Wu Y-R, Cheng M-L, Liu J-L, Lee Y-M, Lee PW, Soong B-W, Chiu DT-Y. Increased oxidative damage and mitochondrial abnormalities in the peripheral blood of Huntington's disease patients. Biochem Biophys Res Commun. 2007;359:335-40.

[175] Borowsky B, Warner J, Leavitt BR, Tabrizi SJ, Roos RAC, Dürr A, Becker C, Sampaio C, Tobin AJ, Schulman H. $8 \mathrm{OHdG}$ is not a biomarker for Huntington disease state or progression. Neurology. 2013.

[176] Moscovitch-Lopatin M, Weiss A, Rosas HD, Ritch J, Doros G, Kegel KB, Difiglia M, Kuhn R, Bilbe G, Paganetti P, Hersch S. Optimization of an HTRF Assay for the Detection of Soluble Mutant Huntingtin in Human Buffy Coats: A Potential Biomarker in Blood for Huntington Disease. PLoS Curr 2, RRN1205. 2010.

[177] Creighton S, Almqvist EW, MacGregor D, Fernandez B, Hogg H, Beis J, Welch JP, Riddell C, Lokkesmoe R, Khalifa M, MacKenzie J, Sajoo A, Farrell S, Robert F, Shugar A, Summers A, Meschino W, Allingham-Hawkins D, Chiu T, Hunter A, Allanson J, Hare H, Schween J, Collins L, Sanders S, Greenberg C, Cardwell S, Lemire E, MacLeod P, Hayden MR. Predictive, pre-natal and diagnostic genetic testing for Huntington's disease: The experience in Canada from 1987 to 2000. Clinical Genetics. 2003;63:462-75.

[178] Kessler S, Field T, Worth L, Mosbarger H. Attitudes of persons at risk for Huntington disease toward predictive testing. Am J Med Genet. 1987;26:259-70.

[179] van Oostrom JCH, Maguire RP, Verschuuren-Bemelmans CC, Veenma-van der Duin L, Pruim J, Roos RAC, Leenders KL. Striatal dopamine D2 receptors, metabolism, 
and volume in preclinical Huntington disease. Neurology 2005;65:941-3.

[180] Andrews TC, Weeks RA, Turjanski N, Gunn RN, Watkins LH, Sahakian B, Hodges JR, Rosser AE, Wood NW, Brooks DJ. Huntington's disease progression. PET and clinical observations. Brain. 1999;122(Pt 12):2353-63.

[181] Paulsen JS, Hayden M, Stout JC, Langbehn DR, Aylward E, Ross CA, Guttman M, Nance M, Kieburtz K, Oakes D, Shoulson I, Kayson E, Johnson S, Penziner E, PREDICTHD Investigators of the Huntington Study Group. Preparing for preventive clinical trials: The Predict-HD study. Arch Neurol. 2006;63:883-90.

[182] Dunah AW, Jeong H, Griffin A, Kim Y-M, Standaert DG, Hersch SM, Mouradian MM, Young AB, Tanese N, Krainc D. Sp1 and TAFII130 transcriptional activity disrupted in early Huntington's disease. Science. 2002;296:2238-43.

[183] Tabrizi SJ, Scahill RI, Dürr A, Roos RA, Leavitt BR, Jones R, Landwehrmeyer GB, Fox NC, Johnson H, Hicks SL, Kennard C, Craufurd D, Frost C, Langbehn DR, Reilmann R, Stout JC, TRACK-HD investigators. Biological and clinical changes in premanifest and early stage Huntington's disease in the TRACK-HD study: The 12-month longitudinal analysis. Lancet Neurology. 2011;10:31-42.

[184] Aylward EH, Nopoulos PC, Ross CA, Langbehn DR, Pierson RK, Mills JA, Johnson HJ, Magnotta VA, Juhl AR, Paulsen JS, PREDICT-HD Investigators and Coordinators of Huntington Study Group. Longitudinal change in regional brain volumes in prodromal Huntington disease. J Neurol Neurosurg Psychiatr. 2011;82:405-10.

[185] van den Bogaard SJA, Dumas EM, Ferrarini L, Milles J, van Buchem MA, van der Grond J, Roos RAC. Shape analysis of subcortical nuclei in Huntington's disease, global versus local atrophy-results from the TRACK-HD study. J Neurol Sci. 2011;307:60-8.

[186] Aylward EH, Liu D, Nopoulos PC, Ross CA, Pierson RK, Mills JA, Long JD, Paulsen JS, Predict-HD Investigators and Coordinators of the Huntington Study Group. Striatal volume contributes to the prediction of onset of Huntington disease in incident cases. Biol Psychiatry. 2012;71:822-8.

[187] Tabrizi SJ, Reilmann R, Roos RAC, Dürr A, Leavitt B, Owen G, Jones R, Johnson H, Craufurd D, Hicks SL, Kennard C, Landwehrmeyer B, Stout JC, Borowsky B, Scahill RI, Frost C, Langbehn DR, TRACK-HD investigators. Potential endpoints for clinical trials in premanifest and early Huntington's disease in the TRACK-HD study: Analysis of 24 month observational data. Lancet Neurology 2012;11:4253.

[188] Ciarmiello A, Giovacchini G, Orobello S, Bruselli L, Elifani F, Squitieri F. (18)F-FDG PET uptake in the pre-Huntington disease caudate affects the time-to-onset independently of CAG expansion size. Eur J Nucl Med Mol Imaging. 2012;39(6): 1030-36.

[189] Duff K, Paulsen JS, Beglinger LJ, Langbehn DR, Stout JC, PREDICT-HD Investigators of the Huntington Study Group. Psychiatric symptoms in Huntington's disease before diagnosis: The predict-HD study. Biol Psychiatry. 2007;62:1341-6

[190] Biglan KM, Ross CA, Langbehn DR, Aylward EH, Stout JC, Queller S, Carlozzi NE, Duff K, Beglinger LJ, Paulsen JS. Motor abnormalities in premanifest persons with Huntington's disease: The PREDICT-HD study. Mov Disord. 2009;24:1763-72.

[191] Bechtel N, Scahill RI, Rosas HD, Acharya T, van den Bogaard SJA, Jauffret C, Say MJ, Sturrock A, Johnson H, Onorato CE, Salat DH, Durr A, Leavitt BR, Roos RAC,
Landwehrmeyer GB, Langbehn DR, Stout JC, Tabrizi SJ, Reilmann R. Tapping linked to function and structure in premanifest and symptomatic Huntington disease. Neurology. 2010;75:2150-60.

[192] Harrington DL, Smith MM, Zhang Y, Carlozzi NE, Paulsen JS, the PREDICT-HD Investigators of the Huntington Study Group. Cognitive domains that predict time to diagnosis in prodromal Huntington disease. J Neurol Neurosurg Psychiatr. 2012;83(6):612-19.

[193] Paulsen JS, Langbehn DR, Stout JC, Aylward E, Ross CA, Nance M, Guttman M, Johnson S, Macdonald M, Beglinger LJ, Duff K, Kayson E, Biglan K, Shoulson I, Oakes D, Hayden M. Detection of Huntington's disease decades before diagnosis: The Predict-HD study. J Neurol Neurosurg Psychiatr. 2008;79:874-80.

[194] Stout JC, Jones R, Labuschagne I, O'Regan AM, Say MJ, Dumas EM, Queller S, Justo D, Santos RD, Coleman A, Hart EP, Dürr A, Leavitt BR, Roos RA, Langbehn DR, Tabrizi SJ, Frost C. Evaluation of longitudinal 12 and 24 month cognitive outcomes in premanifest and early Huntington's disease. J Neurol Neurosurg Psychiatr. 2012;83(7): 687-94.

[195] Hersch SM, Rosas HD. Neuroprotective therapy for Huntington's disease: New prospects and challenges. Expert review of neurotherapeutics. 2001;1:111-8.

[196] Venuto CS, McGarry A, Ma Q, Kieburtz K. Pharmacologic approaches to the treatment of Huntington's disease. Mov Disord. 2012;27:31-41.

[197] Ramaswamy SS, Shannon KMK, Kordower JHJ. Huntington's disease: Pathological mechanisms and therapeutic strategies. Cell Transplant. 2007;16:301-12.

[198] Tabrizi SJ, Langbehn DR, Leavitt BR, Roos RA, Dürr A, Craufurd D, Kennard C, Hicks SL, Fox NC, Scahill RI, Borowsky B, Tobin AJ, Rosas HD, Johnson H, Reilmann R, Landwehrmeyer B, Stout JC, TRACK-HD investigators. Biological and clinical manifestations of Huntington's disease in the longitudinal TRACK-HD study: Cross-sectional analysis of baseline data. Lancet Neurology. 2009;8:791801.

[199] Huntington Study, Group. Tetrabenazine as antichorea therapy in Huntington disease: A randomized controlled trial. Neurology. 2006;66:366-72.

[200] Frank S. Tetrabenazine as anti-chorea therapy in Huntington disease: An open-label continuation study. Huntington Study Group/TETRA-HD Investigators. BMC Neuro. 2009;9:62.

[201] Kenney C, Jankovic J. Tetrabenazine in the treatment of hyperkinetic movement disorders. Expert review of neurotherapeutics. 2006;6:7-17.

[202] Login IS, Cronin MJ, MacLeod RM. Tetrabenazine has properties of a dopamine receptor antagonist. Ann Neurol. 1982;12:257-62.

[203] Pettibone DJ, Totaro JA, Pflueger AB. Tetrabenazineinduced depletion of brain monoamines: Characterization and interaction with selected antidepressants. Eur. J. Pharmacol. 1984;102:425-30.

[204] The Huntington Study Group HART Investigators. A randomized, double-blind, placebo-controlled trial of pridopidine in Huntington's disease. Mov Disord. 2013;28(10):1407-15.

[205] Mestre TA, Ferreira JJ. An evidence-based approach in the treatment of Huntington's disease. Parkinsonism Relat Disord. 2012;18:316-20.

[206] Killoran A, Biglan KM. Therapeutics in Huntington's Disease. Curr Treat Options Neurol. 2012;14(2):137-49. 
[207] Tabrizi SJ, Blamire AM, Manners DN, Rajagopalan B, Styles P, Schapira AHV, Warner TT. High-dose creatine therapy for Huntington disease: A 2-year clinical and MRS study. Neurology. 2005;64:1655-6.

[208] Verbessem P, Lemiere J, Eijnde BO, Swinnen S, Vanhees L, van Leemputte M, Hespel P, Dom R. Creatine supplementation in Huntington's disease: A placebo-controlled pilot trial. Neurology. 2003;61:925-30.

[209] Tabrizi SJ, Blamire AM, Manners DN, Rajagopalan B, Styles P, Schapira AHV, Warner TT. Creatine therapy for Huntington's disease: Clinical and MRS findings in a 1-year pilot study. Neurology. 2003;61:141-2

[210] Hersch SM, Gevorkian S, Marder K, Moskowitz C, Feigin $\mathrm{A}$, Cox $\mathrm{M}$, Como $\mathrm{P}$, Zimmerman $\mathrm{C}$, Lin $\mathrm{M}$, Zhang $\mathrm{L}$, Ulug AM, Beal MF, Matson W, Bogdanov M, Ebbel E, Zaleta A, Kaneko Y, Jenkins B, Hevelone N, Zhang H, Yu H, Schoenfeld D, Ferrante R, Rosas HD. Creatine in Huntington disease is safe, tolerable, bioavailable in brain and reduces serum 8OH2'dG. Neurology. 2006;66:250-2.

[211] Huntington Study, Group. A randomized, placebocontrolled trial of coenzyme Q10 and remacemide in Huntington's disease. Neurology. 2001;57:397-404.

[212] Feigin A, Kieburtz K, Como P, Hickey C, Claude K, Abwender D, Zimmerman C, Steinberg K, Shoulson I. Assessment of coenzyme Q10 tolerability in Huntington's disease. Mov Disord. 1996;11:321-3.

[213] Huntington Study Group Pre2CARE Investigators, Hyson HC, Kieburtz K, Shoulson I, McDermott M, Ravina B, de Blieck EA, Cudkowicz ME, Ferrante RJ, Como P, Frank S, Zimmerman C, Cudkowicz ME, Ferrante K, Newhall K, Jennings D, Kelsey T, Walker F, Hunt V, Daigneault S, Goldstein M, Weber J, Watts A, Beal MF, Browne SE, Metakis LJ. Safety and tolerability of high-dosage coenzyme Q10 in Huntington's disease and healthy subjects. Mov Disord. 2010;25:1924-8.

[214] Vaddadi KS, Soosai E, Chiu E, Dingjan P. A randomised, placebo-controlled, double blind study of treatment of Huntington's disease with unsaturated fatty acids. NeuroReport. 2002:13:29-33.

[215] Dubinsky R, Gray C. CYTE-I-HD: Phase I dose finding and tolerability study of cysteamine (Cystagon) in Huntington's disease. Mov Disord. 2006;21:530-3.

[216] Karpuj MV, Becher MW, Springer JE, Chabas D, Youssef S, Pedotti R, Mitchell D, Steinman L. Prolonged survival and decreased abnormal movements in transgenic model of Huntington disease, with administration of the transglutaminase inhibitor cystamine. Nat Med. 2002;8:143-9.

[217] Dedeoglu A, Kubilus JK, Jeitner TM, Matson SA, Bogdanov M, Kowall NW, Matson WR, Cooper AJL, Ratan RR, Beal MF, Hersch SM, Ferrante RJ. Therapeutic effects of cystamine in a murine model of Huntington's disease. J Neurosci. 2002;22:8942-50.

[218] van Raamsdonk JM, Pearson J, Bailey CDC, Rogers DA, Johnson GVW, Hayden MR, Leavitt BR. Cystamine treatment is neuroprotective in the YAC128 mouse model of Huntington disease. J Neurochem. 2005;95:210-20.

[219] Sittler A, Lurz R, Lueder G, Priller J, Lehrach H, HayerHartl MK, Hartl FU, Wanker EE. Geldanamycin activates a heat shock response and inhibits huntingtin aggregation in a cell culture model of Huntington's disease. Hum Mol Genet. 2001;10:1307-15.

[220] Waza M, Adachi H, Katsuno M, Minamiyama M, Sang C, Tanaka F, Inukai A, Doyu M, Sobue G. 17-AAG, an Hsp90 inhibitor, ameliorates polyglutamine-mediated motor neuron degeneration. Nat Med. 2005;11:1088-95.
[221] Mimnaugh EG, Chavany C, Neckers L. Polyubiquitination and proteasomal degradation of the $185 \mathrm{c}$-erbB-2 receptor protein-tyrosine kinase induced by geldanamycin. J Biol Chem. 1996;271:22796-801.

[222] Bonvini P, Dalla Rosa H, Vignes N, Rosolen A. Ubiquitination and proteasomal degradation of nucleophosminanaplastic lymphoma kinase induced by 17-allylaminodemethoxygeldanamycin: Role of the co-chaperone carboxyl heat shock protein 70-interacting protein. Cancer Res. 2004;64:3256-64.

[223] Fujikake N, Nagai Y, Popiel HA, Okamoto Y, Yamaguchi $\mathrm{M}$, Toda T. Heat shock transcription factor 1-activating compounds suppress polyglutamine-induced neurodegeneration through induction of multiple molecular chaperones. J Biol Chem. 2008;283:26188-97.

[224] Ying W, Du Z, Sun L, Foley KP, Proia DA, Blackman RK, Zhou D, Inoue T, Tatsuta N, Sang J, Ye S, Acquaviva J, Ogawa LS, Wada Y, Barsoum J, Koya K. Ganetespib, a unique triazolone-containing $\mathrm{Hsp} 90$ inhibitor, exhibits potent antitumor activity and a superior safety profile for cancer therapy. Mol Cancer Ther. 2012;11:475-84.

[225] Graham B, Curry J, Smyth T, Fazal L, Feltell R, Harada I, Coyle J, Williams B, Reule M, Angove H, Cross DM, Lyons J, Wallis NG, Thompson NT. The heat shock protein 90 inhibitor, AT13387, displays a long duration of action in vitro and in vivo in non-small cell lung cancer. Cancer Sci. 2012;103:522-7.

[226] Fox JH, Connor T, Chopra V, Dorsey K, Kama JA, Bleckmann D, Betschart C, Hoyer D, Frentzel S, Difiglia M, Paganetti P, Hersch SM. The mTOR kinase inhibitor Everolimus decreases S6 kinase phosphorylation but fails to reduce mutant huntingtin levels in brain and is not neuroprotective in the R6/2 mouse model of Huntington's disease. Mol Neurodegene. 2010;5:26.

[227] Wang X, Zhu S, Drozda M, Zhang W, Stavrovskaya IG, Cattaneo E, Ferrante RJ, Kristal BS, Friedlander RM. Minocycline inhibits caspase-independent and -dependent mitochondrial cell death pathways in models of Huntington's disease. Proc Natl Acad Sci U S A. 2003;100:10483-7.

[228] Chen M, Ona VO, Li M, Ferrante RJ, Fink KB, Zhu S, Bian J, Guo L, Farrell LA, Hersch SM, Hobbs W, Vonsattel JP, Cha JH, Friedlander RM. Minocycline inhibits caspase-1 and caspase- 3 expression and delays mortality in a transgenic mouse model of Huntington disease. Nat Med. 2000;6:797801.

[229] Smith DL, Woodman B, Mahal A, Sathasivam K, GhaziNoori S, Lowden PAS, Bates GP, Hockly E. Minocycline and doxycycline are not beneficial in a model of Huntington's disease. Ann Neurol. 2003;54:186-96.

[230] Diguet E, Fernagut P-O, Wei X, Du Y, Rouland R, Gross C, Bezard E, Tison F. Deleterious effects of minocycline in animal models of Parkinson"s disease and Huntington"s disease. Eur J Neurosci. 2004;19:3266-76.

[231] Hersch S, Fink K, Vonsattel J-P, Friedlander RM. Minocycline is protective in a mouse model of Huntington's disease. Ann Neurol. 2003;54:841-author reply 842-3.

[232] Huntington Study Group DOMINO, Investigators. A futility study of minocycline in Huntington's disease. Mov Disord. 2010;25:2219-24.

[233] Ferrante RJ, Ryu H, Kubilus JK, D'Mello S, Sugars KL, Lee J, Lu P, Smith K, Browne S, Beal MF, Kristal BS, Stavrovskaya IG, Hewett S, Rubinsztein DC, Langley B, Ratan RR. Chemotherapy for the brain: The antitumor antibiotic mithramycin prolongs survival in a mouse model of Huntington's disease. J Neurosci. 2004;24:10335-42. 
[234] Sleiman SF, Langley BC, Basso M, Berlin J, Xia L, Payappilly JB, Kharel MK, Guo H, Marsh JL, Thompson LM, Mahishi L, Ahuja P, MacLellan WR, Geschwind DH, Coppola G, Rohr J, Ratan RR. Mithramycin is a gene-selective Sp1 inhibitor that identifies a biological intersection between cancer and neurodegeneration. J Neurosci. 2011;31:685870.

[235] Zuccato C, Valenza M, Cattaneo E. Molecular mechanisms and potential therapeutical targets in Huntington's disease. Physiol Rev. 2010;90:905-81.

[236] Hockly E, Richon VM, Woodman B, Smith DL, Zhou X, Rosa E, Sathasivam K, Ghazi-Noori S, Mahal A, Lowden PAS, Steffan JS, Marsh JL, Thompson LM, Lewis CM, Marks PA, Bates GP. Suberoylanilide hydroxamic acid, a histone deacetylase inhibitor, ameliorates motor deficits in a mouse model of Huntington's disease. Proc Natl Acad Sci U S A. 2003;100:2041-6.

[237] Ferrante RJ, Kubilus JK, Lee J, Ryu H, Beesen A, Zucker B, Smith K, Kowall NW, Ratan RR, Luthi-Carter R, Hersch SM. Histone deacetylase inhibition by sodium butyrate chemotherapy ameliorates the neurodegenerative phenotype in Huntington's disease mice. J Neurosci. 2003;23: 9418-27.

[238] Gardian G, Browne SE, Choi D-K, Klivenyi P, Gregorio J, Kubilus JK, Ryu H, Langley B, Ratan RR, Ferrante RJ, Beal MF. Neuroprotective effects of phenylbutyrate in the N171$82 \mathrm{Q}$ transgenic mouse model of Huntington's disease. J Biol Chem. 2005;280:556-63.

[239] Benn CL, Butler R, Mariner L, Nixon J, Moffitt H, Mielcarek M, Woodman B, Bates GP. Genetic knock-down of HDAC7 does not ameliorate disease pathogenesis in the R6/2 mouse model of Huntington's disease. PLoS ONE. 2009;4:e5747.

[240] Bobrowska A, Paganetti P, Matthias P, Bates GP. Hdac6 knock-out increases tubulin acetylation but does not modify disease progression in the R6/2 mouse model of Huntington's disease. PLoS ONE. 2011;6:e20696.

[241] Moumné L, Campbell K, Howland D, Ouyang Y, Bates GP. Genetic knock-down of HDAC3 does not modify diseaserelated phenotypes in a mouse model of Huntington's disease. PLoS ONE. 2012;7:e31080.

[242] Ondo WG, Mejia NI, Hunter CB. A pilot study of the clinical efficacy and safety of memantine for Huntington's disease. Parkinsonism Relat Disord. 2007;13:453-4.

[243] Guyot MC, Palfi S, Stutzmann JM, Mazière M, Hantraye $P$, Brouillet E. Riluzole protects from motor deficits and striatal degeneration produced by systemic 3-nitropropionic acid intoxication in rats. NSC. 1997;81:141-9.

[244] Palfi S, Riche D, Brouillet E, Guyot MC, Mary V, Wahl F, Peschanski M, Stutzmann JM, Hantraye P. Riluzole reduces incidence of abnormal movements but not striatal cell death in a primate model of progressive striatal degeneration. Experimental Neurology. 1997;146:135-41.

[245] Mary V, Wahl F, Stutzmann JM. Effect of riluzole on quinolinate-induced neuronal damage in rats: Comparison with blockers of glutamatergic neurotransmission. Neurosci Lett. 1995;201:92-6.

[246] Huntington Study, Group. Dosage effects of riluzole in Huntington's disease: A multicenter placebo-controlled study. Neurology. 2003;61:1551-6.

[247] Morton AJ, Howland DS. Large Genetic Animal Models of Huntington's Disease. J Huntingtons Dis. 2013;2(1):3-19.

[248] Furtado S, Sossi V, Hauser RA, Samii A, Schulzer M, Murphy CB, Freeman TB, Stoessl AJ. Positron emission tomography after fetal transplantation in Huntington's disease. Ann Neurol. 2005;58:331-7.
[249] Gallina P, Paganini M, Lombardini L, Mascalchi M, Porfirio B, Gadda D, Marini M, Pinzani P, Salvianti F, Crescioli C, Bucciantini S, Mechi C, Sarchielli E, Romoli AM, Bertini E, Urbani S, Bartolozzi B, De Cristofaro MT, Piacentini S, Saccardi R, Pupi A, Vannelli GB, Di Lorenzo N. Human striatal neuroblasts develop and build a striatal-like structure into the brain of Huntington's disease patients after transplantation. Experimental Neurology. 2010;222:30-41.

[250] Reuter I, Tai YF, Pavese N, Chaudhuri KR, Mason S, Polkey CE, Clough C, Brooks DJ, Barker RA, Piccini P. Longterm clinical and positron emission tomography outcome of fetal striatal transplantation in Huntington's disease. J Neurol Neurosurg Psychiatr. 2008;79:948-51.

[251] Cicchetti F, Saporta S, Hauser RA, Parent M, Saint-Pierre M, Sanberg PR, Li X-J, Parker JR, Chu Y, Mufson EJ, Kordower JH, Freeman TB. Neural transplants in patients with Huntington's disease undergo disease-like neuronal degeneration. Proc Natl Acad Sci U S A. 2009;106:12483-8.

[252] Keene CD, Sonnen JA, Swanson PD, Kopyov O, Leverenz JB, Bird TD, Montine TJ. Neural transplantation in Huntington disease: Long-term grafts in two patients. Neurology. 2007;68:2093-8.

[253] Capetian P, Knoth R, Maciaczyk J, Pantazis G, Ditter M, Bokla L, Landwehrmeyer GB, Volk B, Nikkhah G. Histological findings on fetal striatal grafts in a Huntington's disease patient early after transplantation. Neuroscience. 2009;160:661-75.

[254] The Hd Ipsc Consortium. Induced Pluripotent Stem Cells from Patients with Huntington's Disease Show CAGRepeat-Expansion-Associated Phenotypes. Cell Stem Cell. 2012;11(2):264-78.

[255] An MC, Zhang N, Scott G, Montoro D, Wittkop T, Mooney S, Melov S, Ellerby LM. Genetic Correction of Huntington's Disease Phenotypes in Induced Pluripotent Stem Cells. Cell Stem Cell. 2012;11(2):253-63.

[256] Cicchetti F, Soulet D, Freeman TB. Neuronal degeneration in striatal transplants and Huntington's disease: Potential mechanisms and clinical implications. Brain. 2011;134:64152.

[257] Gratacòs E, Pérez-Navarro E, Tolosa E, Arenas E, Alberch J. Neuroprotection of striatal neurons against kainate excitotoxicity by neurotrophins and GDNF family members. In, 2001;1287-96.

[258] Dey ND, Bombard MC, Roland BP, Davidson S, Lu M, Rossignol J, Sandstrom MI, Skeel RL, Lescaudron L, Dunbar GL. Genetically engineered mesenchymal stem cells reduce behavioral deficits in the YAC 128 mouse model of Huntington's disease. Behav Brain Res. 2010;214:193-200.

[259] Lucidi-Phillipi CA, Gage FH, Shults CW, Jones KR, Reichardt LF, Kang UJ. Brain-derived neurotrophic factortransduced fibroblasts: Production of BDNF and effects of grafting to the adult rat brain. J Comp Neurol. 1995;354:36176.

[260] Pérez-Navarro E, Canudas AM, Akerund P, Alberch J, Arenas E. Brain-derived neurotrophic factor, neurotrophin-3, and neurotrophin- $4 / 5$ prevent the death of striatal projection neurons in a rodent model of Huntington's disease. J Neurochem. 2000;75:2190-9.

[261] Canals JM, Checa N, Marco S, Akerud P, Michels A, Pérez-Navarro E, Tolosa E, Arenas E, Alberch J. Expression of brain-derived neurotrophic factor in cortical neurons is regulated by striatal target area. J Neurosci. 2001;21: 117-24.

[262] Makar TK, Trisler D, Eglitis MA, Mouradian MM, DhibJalbut S. Brain-derived neurotrophic factor (BDNF) gene 
delivery into the CNS using bone marrow cells as vehicles in mice. Neurosci Lett. 2004;356:215-9.

[263] Giralt A, Friedman HC, Caneda-Ferrón B, Urbán N, Moreno E, Rubio N, Blanco J, Peterson A, Canals JM, Alberch J. BDNF regulation under GFAP promoter provides engineered astrocytes as a new approach for long-term protection in Huntington's disease. Gene Ther. 2010;17: 1294-1308

[264] Tóth ZE, Leker RR, Shahar T, Bratincsak A, Szalayova I, Key S, Palkovits M, Cassiani-Ingoni R, Mezey E. Bone marrow-derived nonreactive astrocytes in the mouse brain after permanent middle cerebral artery occlusion. Stem Cells Dev. 2011;20:539-46

[265] Rossignol J, Boyer C, Lévèque X, Fink KD, Thinard R, Blanchard F, Dunbar GL, Lescaudron L. Mesenchymal stem cell transplantation and DMEM administration in a 3NP rat model of Huntington's disease: Morphological and behavioral outcomes. Behav Brain Res. 2011;217: 369-78.

[266] Nagahara AH, Tuszynski MH. Potential therapeutic uses of BDNF in neurological and psychiatric disorders. Nat Rev Drug Discov. 2011;10:209-19.

[267] Jiang M, Peng Q, Liu X, Jin J, Hou Z, Zhang J, Mori S, Ross CA, Ye K, Duan W. Small-molecule TrkB receptor agonists improve motor function and extend survival in a mouse model of Huntington's disease. Hum Mol Genet. 2013;22(12):2462-70.

[268] Boulle F, Kenis G, Cazorla M, Hamon M, Steinbusch HWM, Lanfumey L, van den Hove DLA. TrkB inhibition as a therapeutic target for CNS-related disorders. Prog Neurobiol. 2012;98:197-206

[269] Ebert AD, Barber AE, Heins BM, Svendsen CN. Ex vivo delivery of GDNF maintains motor function and prevents neuronal loss in a transgenic mouse model of Huntington's disease. Experimental Neurology. 2010;224:155-62.

[270] Pérez-Navarro E, Arenas E, Reiriz J, Calvo N, Alberch J. Glial cell line-derived neurotrophic factor protects striatal calbindin-immunoreactive neurons from excitotoxic damage. NSC. 1996;75:345-52

[271] Pérez-Navarro E, Arenas E, Marco S, Alberch J. Intrastriatal grafting of a GDNF-producing cell line protects striatonigral neurons from quinolinic acid excitotoxicity in vivo. Eur J Neurosci. 1999;11:241-9.

[272] Pérez-Navarro E, Akerud P, Marco S, Canals JM, Tolosa E, Arenas E, Alberch J. Neurturin protects striatal projection neurons but not interneurons in a rat model of Huntington's disease. NSC. 2000;98:89-96.

[273] Emerich DF, Lindner MD, Winn SR, Chen EY, Frydel BR, Kordower JH. Implants of encapsulated human CNTFproducing fibroblasts prevent behavioral deficits and striatal degeneration in a rodent model of Huntington's disease. J Neurosci. 1996;16:5168-81.

[274] Bachoud-Lévi A-C, Deglon N, Nguyen JP, Bloch J, Bourdet C, Winkel L, Remy P, Goddard M, Lefaucheur JP, Brugières P, Baudic S, Cesaro P, Peschanski M, Aebischer P. Neuroprotective gene therapy for Huntington's disease using a polymer encapsulated BHK cell line engineered to secrete human CNTF. Human Gene Therapy. 2000;11: 1723-9.

[275] Bloch J, Bachoud-Lévi A-C, Deglon N, Lefaucheur JP, Winkel L, Palfi S, Nguyen JP, Bourdet C, Gaura V, Remy $\mathrm{P}$, Brugières $\mathrm{P}$, Boisse M-F, Baudic $\mathrm{S}$, Cesaro $\mathrm{P}$, Hantraye P, Aebischer P, Peschanski M. Neuroprotective gene therapy for Huntington's disease, using polymer-encapsulated cells engineered to secrete human ciliary neurotrophic fac- tor: Results of a phase I study. Human Gene Therapy. 2004; 15:968-75.

[276] Benraiss A, Bruel-Jungerman E, Lu G, Economides AN, Davidson B, Goldman SA. Sustained induction of neuronal addition to the adult rat neostriatum by AAV4-delivered noggin and BDNF. Gene Ther. 2011;19:483-93.

[277] McBride JL, During MJ, Wuu J, Chen EY, Leurgans SE, Kordower JH. Structural and functional neuroprotection in a rat model of Huntington's disease by viral gene transfer of GDNF. Experimental Neurology. 2003;181:213-23.

[278] McBride JL, Ramaswamy S, Gasmi M, Bartus RT, Herzog CD, Brandon EP, Zhou L, Pitzer MR, Berry-Kravis EM, Kordower JH. Viral delivery of glial cell line-derived neurotrophic factor improves behavior and protects striatal neurons in a mouse model of Huntington's disease. Proc Natl Acad Sci U S A. 2006;103:9345-50.

[279] Gasmi M, Brandon EP, Herzog CD, Wilson A, Bishop KM, Hofer EK, Cunningham JJ, Printz MA, Kordower JH, Bartus RT. AAV2-mediated delivery of human neurturin to the rat nigrostriatal system: Long-term efficacy and tolerability of CERE-120 for Parkinson's disease. Neurobiology of Disease. 2007;27:67-76.

[280] Marks WJ, Bartus RT, Siffert J, Davis CS, Lozano A, Boulis N, Vitek J, Stacy M, Turner D, Verhagen L, Bakay R, Watts R, Guthrie B, Jankovic J, Simpson R, Tagliati M, Alterman R, Stern M, Baltuch G, Starr PA, Larson PS, Ostrem JL, Nutt J, Kieburtz K, Kordower JH, Olanow CW. Gene delivery of AAV2-neurturin for Parkinson's disease: A double-blind, randomised, controlled trial. Lancet Neurology. 2010;9:1164-72.

[281] Hickey P, Stacy M. AAV2-neurturin (CERE-120) for Parkinson's disease. Expert Opin Biol Ther. 2013;13:137-45.

[282] Bartus RT, Baumann TL, Siffert J, Herzog CD, Alterman R, Boulis N, Turner DA, Stacy M, Lang AE, Lozano AM, Olanow CW. Safety/feasibility of targeting the substantia nigra with AAV2-neurturin in Parkinson patients. Neurology. 2013;80(18):1698-701.

[283] Ramaswamy S, McBride JL, Herzog CD, Brandon E, Gasmi M, Bartus RT, Kordower JH. Neurturin gene therapy improves motor function and prevents death of striatal neurons in a 3-nitropropionic acid rat model of Huntington's disease. Neurobiology of Disease. 2007;26: 375-84.

[284] Southwell AL, Khoshnan A, Dunn DE, Bugg CW, Lo DC, Patterson PH. Intrabodies binding the proline-rich domains of mutant huntingtin increase its turnover and reduce neurotoxicity. J Neurosci. 2008;28:9013-20.

[285] Southwell AL, Ko J, Patterson PH. Intrabody gene therapy ameliorates motor, cognitive, and neuropathological symptoms in multiple mouse models of Huntington's disease. J Neurosci. 2009;29:13589-602.

[286] Wang C-E, Zhou H, McGuire JR, Cerullo V, Lee B, Li S-H, Li X-J. Suppression of neuropil aggregates and neurological symptoms by an intracellular antibody implicates the cytoplasmic toxicity of mutant huntingtin. The Journal of Cell Biology. 2008;181:803-16.

[287] Bauer PO, Goswami A, Wong HK, Okuno M, Kurosawa M, Yamada M, Miyazaki H, Matsumoto G, Kino Y, Nagai Y, Nukina N. Harnessing chaperone-mediated autophagy for the selective degradation of mutant huntingtin protein. Nat Biotechnol. 2010;28:256-63.

[288] Zeitlin S, Liu JP, Chapman DL, Papaioannou VE, Efstratiadis A. Increased apoptosis and early embryonic lethality in mice nullizygous for the Huntington's disease gene homologue. Nat Genet. 1995;11:155-63. 
[289] Lu X-H, Yang XW. "Huntingtin holiday": Progress toward an antisense therapy for Huntington's disease. Neuron. 2012;74:964-6.

[290] Rodriguez-Lebron E, Denovan-Wright EM, Nash K, Lewin AS, Mandel RJ. Intrastriatal rAAV-mediated delivery of anti-huntingtin shRNAs induces partial reversal of disease progression in R6/1 Huntington's disease transgenic mice. Mol Ther. 2005; 12:618-33.

[291] Boudreau RL, Spengler RM, Davidson BL. Rational Design of Therapeutic siRNAs: Minimizing Off-targeting Potential to Improve the Safety of RNAi Therapy for Huntington's Disease. Mol Ther. 2011;19(12):2169-77.

[292] McBride JL, Pitzer MR, Boudreau RL, Dufour B, Hobbs T, Ojeda SR, Davidson BL. Preclinical Safety of RNAiMediated HTT Suppression in the Rhesus Macaque as a Potential Therapy for Huntington's Disease. Mol Ther. 2011;19:2152-62.

[293] Grondin R, Kaytor MD, Ai Y, Nelson PT, Thakker DR, Heisel J, Weatherspoon MR, Blum JL, Burright EN, Zhang Z, Kaemmerer WF. Six-month partial suppression of Huntingtin is well tolerated in the adult rhesus striatum. Brain. 2012;135:1197-209.

[294] McBride JL, Boudreau RL, Harper SQ, Staber PD, Monteys AM, Martins I, Gilmore BL, Burstein H, Peluso RW, Polisky B, Carter BJ, Davidson BL. Artificial miRNAs mitigate shRNA-mediated toxicity in the brain: Implications for the therapeutic development of RNAi. Proc Natl Acad Sci U S A. 2008;105:5868-73.

[295] Franich NR, Fitzsimons HL, Fong DM, Klugmann M, During MJ, Young D. AAV vector-mediated RNAi of mutant huntingtin expression is neuroprotective in a novel genetic rat model of Huntington's disease. Mol Ther. 2008;16:94756.

[296] Boudreau RL, McBride JL, Martins I, Shen S, Xing Y, Carter BJ, Davidson BL. Nonallele-specific silencing of mutant and wild-type huntingtin demonstrates therapeutic efficacy in Huntington's disease mice. Mol Ther. 2009;17:1053-63.

[297] Kordasiewicz HB, Stanek LM, Wancewicz EV, Mazur C, McAlonis MM, Pytel KA, Artates JW, Weiss A, Cheng SH, Shihabuddin LS, Hung G, Bennett CF, Cleveland DW. Sustained therapeutic reversal of Huntington's disease by transient repression of huntingtin synthesis. Neuron. 2012;74:1031-44.

[298] Lombardi MS, Jaspers L, Spronkmans C, Gellera C, Taroni F, Di Maria E, Donato SD, Kaemmerer WF. A majority of Huntington's disease patients may be treatable by individualized allele-specific RNA interference. Experimental Neurology. 2009;217:312-9.

[299] Carroll JB, Warby SC, Southwell AL, Doty CN, Greenlee S, Skotte N, Hung G, Bennett CF, Freier SM, Hayden MR. Potent and selective antisense oligonucleotides targeting single-nucleotide polymorphisms in the Huntington disease gene/allele-specific silencing of mutant huntingtin. Mol Ther. 2011;19:2178-85.

[300] Southwell AL, Warby SC, Carroll JB, Doty CN, Skotte NH, Zhang W, Villanueva EB, Kovalik V, Xie Y, Pouladi MA,
Collins JA, Yang XW, Franciosi S, Hayden MR. A fully humanized transgenic mouse model of Huntington disease. Hum Mol Genet. 2013;22(1):18-34.

[301] Gagnon KT, Pendergraff HM, Deleavey GF, Swayze EE, Potier P, Randolph J, Roesch EB, Chattopadhyaya J, Damha MJ, Bennett CF, Montaillier C, Lemaitre M, Corey DR. Allele-selective inhibition of mutant huntingtin expression with antisense oligonucleotides targeting the expanded CAG repeat. Biochemistry. 2010;49:10166-78.

[302] Matthews RT, Yang L, Browne S, Baik M, Beal MF. Coenzyme Q10 administration increases brain mitochondrial concentrations and exerts neuroprotective effects. Proc Natl Acad Sci U S A. 1998;95:8892-7.

[303] Andreassen OA, Dedeoglu A, Ferrante RJ, Jenkins BG, Ferrante KL, Thomas M, Friedlich A, Browne SE, Schilling G, Borchelt DR, Hersch SM, Ross CA, Beal MF. Creatine increase survival and delays motor symptoms in a transgenic animal model of Huntington's disease. Neurobiology of Disease. 2001;8:479-91.

[304] Borrell-Pagès M, Canals JM, Cordelières FP, Parker JA, Pineda JR, Grange G, Bryson EA, Guillermier M, Hirsch E, Hantraye P, Cheetham ME, Néri C, Alberch J, Brouillet E, Saudou F, Humbert S. Cystamine and cysteamine increase brain levels of BDNF in Huntington disease via HSJ1b and transglutaminase. J Clin Invest. 2006;116:1410-24.

[305] Gibrat C, Bousquet M, Saint-Pierre M, Lévesque D, Calon F, Rouillard C, Cicchetti F. Cystamine prevents MPTPinduced toxicity in young adult mice via the up-regulation of the brain-derived neurotrophic factor. Prog Neuropsychopharmacol Biol Psychiatry. 2010;34:193-203.

[306] Ehrnhoefer DE, Duennwald M, Markovic P, Wacker JL, Engemann S, Roark M, Legleiter J, Marsh JL, Thompson LM, Lindquist S, Muchowski PJ, Wanker EE. Green tea (-)-epigallocatechin-gallate modulates early events in huntingtin misfolding and reduces toxicity in Huntington's disease models. Hum Mol Genet. 2006; 15:2743-2751.

[307] Ferrante RJ, Andreassen OA, Dedeoglu A, Ferrante KL, Jenkins BG, Hersch SM, Beal MF. Therapeutic effects of coenzyme Q10 and remacemide in transgenic mouse models of Huntington's disease. J Neurosci. 2002;22:1592-9.

[308] Qiu Z, Norflus F, Singh B, Swindell MK, Buzescu R, Bejarano M, Chopra R, Zucker B, Benn CL, DiRocco DP, Cha J-HJ, Ferrante RJ, Hersch SM. Sp1 is up-regulated in cellular and transgenic models of Huntington disease, and its reduction is neuroprotective. J Biol Chem. 2006;281:1667280.

[309] Mielcarek M, Benn CL, Franklin SA, Smith DL, Woodman B, Marks PA, Bates GP. SAHA decreases HDAC 2 and 4 levels in vivo and improves molecular phenotypes in the R6/2 mouse model of Huntington's disease. PLoS ONE. 2011;6:e27746.

[310] Crook ZR, Housman DE. Dysregulation of dopamine receptor D2 as a sensitive measure for Huntington disease pathology in model mice. Proc Natl Acad Sci U S A. 2012;109:7487-92. 